\title{
Políticas y prácticas para gestionar los conflictos de interés en Europa: una visión comparada
}

Manuel Villoria

\section{Introducción}

En este informe se van a exponer de forma sumaria los diversos enfoques y aproximaciones que nueve países de la Unión Europea están usando para gestionar los conflictos de interés en el sector público. De estos países, seis son antiguos miembros (Reino Unido, Alemania, Francia, Italia, España y Portugal) y tres son miembros recientes (Letonia, Polonia y Hungría) de la Unión Europea. El informe se basa en una investigación previa realizada para la Organización para la Cooperación y el Desarrollo Económicos (OCDE) con el título de "Assessment of conflict-of-interest policies and practices: a comparative review". Dicho documento tenía como objetivo aportar información y criterios de actuación al Gobierno de la República Checa de cara a reformar su normativa de gestión de los conflictos de interés en el sector público. También se fundamenta en otro documento de la OCDE, elaborado asimismo por el autor de este trabajo, con el título de "Modernising conflict of interest policy and practice: the Spanish 
experience", publicado por la propia OCDE como documento OLIS con la referencia GOV/PGC/ETH 2006(2) y utilizado para un Expert Meeting.

$\mathrm{El}$ informe tendrá cinco partes, consistentes en un marco conceptual, tres capítulos intermedios y unas recomendaciones finales. La primera parte presentará el marco conceptual y de definiciones con las que poder entender de qué hablamos cuando hablamos de corrupción y de conflictos de interés en el sector público. El segundo capítulo tratará de explicar las razones existentes tras estas políticas de regulación y tratamiento de los conflictos de interés y la importancia de ellas para el funcionamiento adecuado de la democracia. En última instancia, debería explicar la racionalidad que existe tras las diferentes políticas al definir y establecer restricciones para actividades políticas, económicas y sociales que, en otras circunstancias, serían plenamente legítimas para las personas implicadas. En este capítulo se analizará la gestión de los conflictos de interés en el marco de las políticas tendentes a prevenir y combatir la corrupción.

El tercer capítulo explicará las características de esta política pública en el contexto de las teorías y enfoques sobre políticas públicas. Estas políticas de prevención de la corrupción y, en concreto, éstas relacionadas con la gestión de los conflictos de interés son políticas especiales, con sus propios y específicos rasgos. En el informe se intentarán explicar las peculiaridades existentes tras las mismas y los dilemas a que hacen frente.

El cuarto capítulo examina los puntos comunes en las estructuras, métodos y procesos utilizados para gestionar los conflictos de interés en los países estudiados. También explicitará las principales diferencias en los marcos legales, medios de implantación, mecanismos de evaluación y medios de ejecución. Finalmente, incluirá una visión crítica de las ventajas y desventajas relacionadas con la utilidad de los instrumentos empleados. La parte final del informe se centrará en las recomendaciones relativas a cómo formular e implantar políticas de este tipo, e incluye unas conclusiones.

\section{Marco conceptual}

\section{Definición de conflictos de interés}

Este informe emplea principalmente como referencia conceptual la definición genérica de la OCDE sobre conflictos de interés. La definición es la siguiente:

"El conflicto de intereses de los responsables públicos ${ }^{1}$ es un conflicto entre obligaciones públicas e interés privado que puede indebidamente influir en el cumplimiento de sus obligaciones y responsabilidades" (OCDE, 2004).

De esta definición surge como consecuencia el reconocimiento de que se incluyen en la misma no sólo las situaciones en las que, de hecho, existe un inaceptable conflicto entre los intereses como persona privada de un responsable público y sus obligaciones como tal responsable público, sino también aquellas situaciones en las que existe un aparente conflicto de interés o un potencial conflicto de interés. En suma, a efectos de la OCDE, el conflicto puede ser aparente: pueden darse pero no se dan los conflictos. O puede ser potencial: podría haber conflicto en el futuro si el funcionario/a asumiera ciertas responsabilidades. Pero ambos tipos de conflicto, aun cuando no sean reales y actuales, se incluyen en la definición y se regulan.

Un conflicto aparente de intereses se da cuando hay un interés personal implicado que podría hacer pensar razonablemente a los ciudadanos que dicho interés ejerce una influencia indebida en el 
responsable público, aun cuando, de hecho, no la ejerza o, incluso, cuando de hecho no exista tal influencia. Por ejemplo, si el Director General de Farmacia del Gobierno de Brasil posee cinco farmacias en el país tendrá un conflicto de intereses aparente, al menos, al tomar decisiones sobre regulación farmacéutica; podría ser que dicho Director actuara en la práctica de forma muy imparcial, pero su imagen y la del Gobierno quedarían siempre en entredicho y sobre sus decisiones caería un ámbito de sospecha. Este tipo de situaciones generan un potencial de duda sobre la integridad del responsable público, o sobre la integridad en su conjunto de la organización donde éste trabaja, que recomendarían que tal tipo de situaciones se evitaran, aun cuando no exista real conflicto de intereses. La imagen y el prestigio de las instituciones públicas recomiendan que se eviten conflictos de interés aparentes.

El conflicto potencial de intereses puede existir cuando y donde un responsable público tiene intereses privados o personales que podrían causarle un conflicto de intereses a surgir en algún momento en el futuro, aunque ahora no exista tal conflicto. Por ejemplo, si la esposa del responsable público va a ser nombrada en un mes como directora de marketing o CEO de alguna compañía farmacéutica y el responsable es Director General de Farmacia, y conoce tal dato, puede que sus decisiones ya empiecen a ser afectadas por tal futuro nombramiento que, en todo caso, sí afectará en el futuro a este Director.

Como consecuencia de todo ello, la definición básica aquí usada asume que, si una persona razonable, conociendo todos los datos relevantes, pudiera concluir que los intereses privados o personales del responsable público estarían en condiciones de influir impropiamente en su conducta o toma de decisiones, o en la imagen del Estado, dicha situación debe evitarse.

\section{Definición de corrupción}

En una excelente síntesis, Francesco Kjellberg (2000) define la corrupción (pública) como una quiebra de las normas legales (concepción jurídica) o de las normas éticas no escritas (concepción ética) pero con apoyo social generalizado
"Se incluyen en

la definición de conflicto de intereses

no sólo las

situaciones en las

que existe conflicto

entre los intereses

como persona

privada de un

responsable público

y sus obligaciones

como tal, sino

también aquellas

en las que existe un

aparente o un

potencial conflicto." (concepción sociológica), relativas a cómo se debe ejercer el servicio público, para proporcionar servicios o beneficios a ciertos grupos o ciudadanos de forma oculta (concepción política), con voluntad de ganancia directa o indirecta en mente (concepción económica).

De esta definición, además, surgen cuatro tipos posibles de actividades corruptas. 
a) Primero, aquellas que quiebran normas legales y cuyo resultado son beneficios directos para el político o burócrata correspondiente. Es éste el supuesto más comúnmente entendido como corrupción, son los sobornos y cohechos - "bustarella" en italiano, "pot de vin" en francés, "kickback" en inglés o las malversaciones de fondos públicos. Es este tipo de corrupción la que se mide sobre todo en los famosos índices de corrupción de Transparency International, índices que, aunque suponen un avance importantísimo, por centrarse sólo en un tipo de corrupción y por otras razones, tienen una validez limitada. Por esta razón, Transparency ha generado otros instrumentos de medición recientemente, como el Barómetro Global. Con este tipo de corrupción directa, brutal e ilegal algunos gobernantes han conseguido hacerse inmensamente ricos, como fue el caso de Suharto en Indonesia, al que se le atribuyen entre 15.000 y 30.000 millones de dólares en beneficios. En ocasiones, los beneficios, aunque directos, son de difícil comprobación, pues son diferidos o son no monetarios. Estos supuestos, como hemos indicado, son de más difícil control pues el beneficio muchas veces es no tangible inmediatamente. Es el caso de ciertas resoluciones dictadas a sabiendas de que son injustas o el tráfico de influencias, que se hacen sabiendo que se le debe algo al corrupto, pero los beneficios concretos no se perciben inmediatamente, sino que vendrán en su momento: puede ser una mera información para que compre ciertas acciones, o su reforzamiento en el partido y aseguramiento de un puesto en las próximas listas a congresistas, etc.

b) Segundo, aquellas que implican quiebra de normas legales pero con beneficios indirectos para el corrupto. Aquí se incorporarían todos aquellos supuestos en los que se incumplen normas de concurrencia en la contratación pública o en la concesión de subvenciones para favorecer a grupos que financian al partido político del corrupto. En estos casos se incumple la norma para favorecer al partido, no al propio decisor directamente. Ciertas personas ejercen la labor de recaudadores para el partido abusando de puestos públicos; alguna vez, aunque raramente, no se benefician personalmente de tal labor, sino que realizan este trabajo sucio como una forma de militancia. Normalmente, su beneficio es indirecto, seguir ocupando puestos públicos y conseguir incluso ascensos en la escala administrativa o en el partido.

c) Tercero, aquellas que implican quiebra de normas éticas socialmente aceptadas - al menos por ciertas élites intelectuales -, con beneficio directo para el corrupto. Es el supuesto de ciertas informaciones no plenamente secretas, pero a las que se tiene acceso privilegiado, pasadas al amigo o utilizadas personalmente con beneficio tangible directo. Por ejemplo, el alto cargo que favorece a empresas de familiares en convocatorias de subvenciones, en las que subordinados suyos deciden libremente, y que dichas empresas ganan no por fraude en las decisiones, sino por la información que éstas tienen sobre cómo presentar los proyectos, información pasada obviamente por el corrupto pero sin posibilidad real de demostrarse y sin claro incumplimiento de normas jurídicas; o el abuso de cargo para obtener ciertos descuentos, regalos, consumiciones gratuitas o priorización en la consecución de permisos o licencias, sin que exista ninguna resolución o acto claramente fraudulento o ilegal. Así, por ejemplo, un ministro puede conseguir un 
crédito de un banco a un interés tan bajo que es un verdadero regalo, o puede comprase un piso a un precio irrisorio por un descuento que le dan por ser quien es, etc. También es muy común, por desgracia, el supuesto de parlamentarios que reciben financiación para su campaña de lobbies o grupos de interés a cambio de que apoyen leyes que favorecen a los lobbies, aunque dañen el interés común.

d) Cuarto, aquellas que implican la quiebra de normas éticas socialmente aceptadas - al menos por ciertas élites -, pero con beneficio indirecto para el corrupto. Éste es el supuesto de más difícil control, pero no por ello menos frecuente. En general, es muy común que a través de la financiación legal se influya en la definición de políticas posteriormente. En concreto, tal influencia supone que el responsable público correspondiente actúe de forma que, en la elaboración de normas, se favorezca a grupos que han financiado al partido gobernante. También puede consistir en la concesión de contratos, respetando todas las normas formalmente, para que los contratistas influyan favorablemente en el tratamiento informativo que medios afines a ellos dan del partido al que pertenece el concedente. Hoy es muy difícil, en economías avanzadas y globalmente interconectadas, poner claros límites al uso del poder, pues las posibilidades de actuar de forma fraudulenta son infinitas. La sofisticación se produce cuanto más avanzado es el país afectado, de manera que quedan ocultos al escrutinio público numerosos hechos que, realmente, implican abuso de poder y beneficio privado. Sin embargo, en países subdesarrollados la corrupción es mucho más directa e impactante, por lo que se tiende a ser mucho más críticos con ella que con la propia de los países avanzados.

\section{Diferencias de conflicto de interés con el concepto de corrupción}

El conflicto de intereses es un prerrequisito para la corrupción, pero no tiene por qué acabar en ella. El conflicto, como acabamos de ver, puede ser aparente pueden darse pero no se dan los conflictos. $O$ puede ser potencial: podría haber conflicto en el futuro si el funcionario/a o sus familiares asumieran ciertas responsabilidades. Pero para que exista corrupción el conflicto tiene que ser real y la actuación del responsable público tiene que desembocar en una decisión o inacción en la que prime el interés privado sobre el público. Por todo ello, surgen tres posibilidades: a) supuestos de conflicto de interés sin corrupción. Por ejemplo, un responsable público que tiene que tomar una decisión en la que están afectados familiares directos pide abstenerse de resolver, dado el conflicto; b) supuestos de corrupción donde el conflicto de intereses es un ingrediente claro del resultado final. Por ejemplo, un ministro interviene en las actividades de su gobierno para que se regule a favor de una empresa propiedad de su esposa. c) casos de corrupción en los que no hay indicios de conflicto de interés. Por ejemplo, un agente electoral de un partido compra el voto a unos campesinos a cambio de unos reales. $\mathrm{O}$ un responsable público cobra un soborno por tomar una decisión que habría tomado en cualquier caso, sin que, por ello, exista conflicto de interés al tomar la decisión.

Dicho esto, a pesar de las diferencias, es obvio que cualquier país que quiera luchar contra la corrupción debe tener una legislación de conflictos de interés e incompatibilidades avanzada y rigurosa, que impidan los conflictos de interés reales, posibles e, incluso, aparentes. En el tratamiento de los conflictos de interés se 
pueden mantener dos tipos de estrategias, una sería la de intentar evitar que los conflictos se produzcan (opción preventiva), la otra consistiría en, reconociendo que inevitablemente existen y existirán conflictos, construir sistemas de normas y procedimientos para que, cuando surjan, se asegure que los responsables públicos actuarán defendiendo el interés público (opción reactiva). En realidad, ambas estrategias tienden en la vida real a mezclarse, sin que se opte normalmente por sólo una de ellas. Además, lo lógico es que las políticas para prevenir y resolver los conflictos de interés se inserten en una política más amplia para prevenir y luchar contra la corrupción. Ciertamente, todo responsable público (político o funcionario) sufre o puede sufrir conflictos de interés, pero a efectos del sistema existen colectivos especialmente poderosos o vulnerables sobre los que hay que actuar prioritariamente: por ejemplo, los altos cargos, los responsables de contrataciones y compras, los jueces, etc.

\section{Medidas utilizadas para prevenir y regular los conflictos de interés}

Entre las medidas que se vinculan a la prevención y regulación de los conflictos de interés se destacarían las siguientes:

a) Restricciones en el ejercicio de empleos adicionales al principal empleo público. Aquí pueden darse todo tipo de incompatibilidades tanto con otro empleo público como con empleo en el sector privado. Sobre todo, cuando se trata de altos cargos o de jueces, lo normal es la prohibición absoluta de cualquier otro empleo público o privado. Cuando se trata de funcionarios de nivel medio o subalterno esta prohibición, en lo relativo a puestos de trabajo en el sector privado se puede flexibilizar, siempre que se cumplan las obligaciones del cargo público. b) Declaración de ingresos personales. Con esta medida, aplicable sobre todo a altos cargos y funcionarios en puestos de responsabilidad, se pretende conocer la procedencia de los ingresos, de manera que se controlen posibles fuentes de influencia indebida en su conducta. De cara a la lucha contra la corrupción, la declaración de ingresos permite, también, conocer los ingresos extraordinarios y descubrir enriquecimientos súbitos que necesitan explicación.

c) Declaración de ingresos familiares. Esta medida es muy similar en sus fines a la anterior, pero amplía la esfera subjetiva de control, de manera que se conozcan posibles conflictos derivados de las fuentes de ingresos de familiares muy cercanos. También en la lucha contra la corrupción el conocimiento de las fuentes de ingresos familiares es muy importante, porque extraordinarios enriquecimientos de hijos o esposa/o durante el mandato del alto cargo, por ejemplo, pueden estar vinculados a actividades ilícitas o inmorales. Así, si la esposa de un Alcalde o de un Secretario de Estado se convierte de repente, coincidiendo con el mandato de su marido, en una empresaria de gran éxito, conocer la procedencia de ingresos y, posteriormente, qué tipo de negocios realiza puede ser muy importante de cara a luchar contra la corrupción. En algunos países, en la lucha contra el nepotismo, se ha llegado a prohibir a los familiares (hasta el cuarto grado) de los miembros del gobierno (presidentes, vicepresidentes y ministros) la ocupación de ningún cargo público de designación política, en estos casos, el conocimiento de los ingresos hace más fácil el control del cumplimiento de esta norma.

d) Declaración de patrimonio personal. Hay personas que cuando ingresan en política o cuando ocupan 
puestos administrativos ya poseen una gran fortuna, de forma que la revelación de ese patrimonio puede ayudar a conocer fuentes de conflicto de interés. Además, el descubrimiento de tal fortuna durante el mandato podría ser fuente de un escándalo, basado en la manipulación de datos, si no existiera información previa. Conocer desde el inicio ese patrimonio reduce las posibilidades de escándalos innecesarios y dañosos para la imagen de lo público. Pero lo normal es que las personas no posean tal fortuna, y si durante el mandato se adquiriese un patrimonio incoherente con los ingresos conocidos, al conocerse el patrimonio de partida, existirían fundamentos para iniciar investigaciones sobre posible corrupción; en tal caso, el análisis de los movimientos de cuentas (al menos de las no situadas en paraísos fiscales) permite ir conociendo el sistema de ingresos y el origen del patrimonio irregular. El "Caso Roldán” en España es un buen ejemplo de enriquecimiento injustificado en una persona que acudió a la política como medio de vida, sin patrimonio previo, y que tras su paso por la Dirección General de la Guardia Civil se convirtió en un acaudalado propietario, el análisis de su patrimonio y de los orígenes del mismo permitió su acusación y posterior condena por delitos de corrupción. Para los supuestos en que el análisis de las cuentas bancarias y los ingresos no permitan justificar los incrementos patrimoniales, la reciente entrada en vigor de la "Convención de las Naciones Unidas contra la Corrupción” aporta el tipo delictivo del "enriquecimiento ilícito" como instrumento de lucha contra la corrupción. En todo caso, hoy en día es bastante normal que personas de clase media puedan tener acciones en empresas y su interés en que la empresa reporte beneficios puede condicionar su toma de decisiones en el sector público, de ahí la conveniencia de conocer sus activos financieros o participaciones en sociedades.

e) Declaración de patrimonio familiar. Aquí, como en el caso de los ingresos, el conocimiento del patrimonio del cónyuge o de los ascendientes y descendientes es importante para conocer fuentes de conflicto y para facilitar la lucha contra la corrupción. Por ejemplo, un ministro de Agricultura puede ver comprometida su

"La corrupción no se limita al soborno. Incluye todos aquellos supuestos en los que sin soborno $y$ sin delito se priorizan los intereses privados sobre el interés general. Es aquí donde aparece el conflicto de intereses comofuente esencial de corrupción."

imparcialidad si su esposa es propietaria de grandes explotaciones agrícolas o un funcionario encargado de contrataciones puede tener conflictos importantes si su esposa es propietaria de una empresa que contrata directamente con el Ministerio donde éste ejerce su función. En muchos casos, además, el patrimonio familiar es fundamental para la ocultación de ingresos indebidos: los pisos a nombre de hijos y 
familiares son prácticas demasiado comunes como para no tomar medidas para controlarlas.

f) Declaración de regalos. En el ejercicio del cargo, y como consecuencia del mismo, pueden recibirse regalos oficiales (de gobiernos extranjeros, por ejemplo) y privados. Esos regalos podrían comprometer la imparcialidad y, por ello, ser fuente de conflictos de interés, de ahí que, a partir de un determinado valor económico, se prohíba en algunos países la aceptación de regalos. No obstante, cuando por razones de cortesía y de respeto institucional sea conveniente aceptarlos, la normativa a menudo establece que es necesario declararlos e incorporarlos al patrimonio estatal. También es cierto que en la aceptación de regalos es diferente la aceptación antes de prestar el servicio o tomar la decisión que después, en el primer caso puede comprometer la decisión o la prestación, en el segundo puede ser una muestra de agradecimiento por una decisión tomada imparcialmente. En cualquier caso, para evitar pervertir la imagen de lo público conviene evitar ambos tipos de regalos, aunque la casuística puede obligar a matizar la regla en ciertos casos. Por ejemplo, en el caso de que se dé por agradecimiento y con valor económico ínfimo, por ejemplo, unas flores a la enfermera que cuidó amablemente a un familiar, podría preverse una cierta condescendencia atendiendo a las circunstancias del caso.

g) Declaración de intereses privados relevantes para la gestión de contratos. La participación en empresas y los activos financieros que se posean pueden condicionar la toma de decisiones en un área como la de contratación, para ello se obliga, como antes vimos, a la declaración de patrimonio en múltiples legislaciones.
Pero esa declaración no basta para conocer todas las fuentes de conflicto, así, por ejemplo, un responsable público puede haber trabajado durante años en una empresa, antes de ingresar en la Administración, y tener una relación de amistad o de enemistad con sus propietarios. Si esa empresa contrata con la organización en que se trabaja, y el responsable público está encargado de la gestión de contratos, se presenta un caso de conflicto de intereses. Otro ejemplo de conflicto que puede darse es cuando el responsable de contratación ha sido abogado o representante legal de una empresa o de una asociación y tiene que tomar decisiones sobre si adjudicarle contratos o subvenciones o si denunciar un contrato por incumplimiento. De ahí que se obligue en algunas normativas a declarar las actividades previas realizadas en los últimos años y a abstenerse de decidir en ese caso.

h) Declaración de intereses privados relevantes para la toma de decisiones. En este caso, como en el anterior, se trata de evitar que patrimonio y actividades previas puedan condicionar la imparcialidad de la decisión actual. Por ejemplo, un funcionario de alto nivel que ha sido abogado de una gran empresa y que la defendió en un pleito con la Administración en la que ahora ocupa un alto cargo, no puede tomar una decisión que pueda condicionar el resultado final del pleito. $\mathrm{O}$ un inspector de Hacienda en activo que ha sido previamente asesor fiscal de unas determinadas empresas, no puede tomar ahora decisiones sobre expedientes que afectan a esas empresas. En ambos casos, el funcionario debería abstenerse de decidir en esos casos. Pero para controlar previamente la situación conviene que declare sus actividades previas de los últimos años. 
i) Declaración de intereses privados relevantes para quienes participan en la toma de decisiones como consejeros o informantes. En estos casos, a quienes afecta la obligación es a personas que no toman decisiones pero que influyen con sus consejos e informes en la toma final de la decisión. Es innegable que si un experto tiene que informar sobre la compra de un avión de combate y su informe es muy relevante para la toma de decisión final, el hecho de que antes de ingresar en la Administración haya trabajado en una empresa de construcción aeronáutica o que posea acciones en la misma, puede condicionar su informe y la decisión final si aquélla se presenta al concurso, de ahí que convenga conocer tal circunstancia.

j) Seguridad y control en el acceso a información privilegiada. Ciertas personas trabajan en áreas en las que se maneja información muy relevante para la economía nacional o para su seguridad, de ahí que convenga clarificar a quién y cómo podrían beneficiar estas personas si se decidieran a revelar tal información y, posteriormente, tomar medidas para evitar la posibilidad. Ello puede llevar a incompatibilidades muy exigentes y a declaraciones de intereses continuas y muy detalladas. Incluso, en ciertos países, ello da lugar a investigaciones oficiales sobre su vida privada.

k) Restricciones y control de actividades privadas con posterioridad al cese. Una forma de capturar políticas y decisiones, por parte de empresas, ONG's y grupos de interés, es el de ofrecer altos cargos en dichas organizaciones a los responsables públicos para cuando abandonen el gobierno. Para evitar este tipo de situaciones, con toda su carga de conflicto de interés y también de soborno diferido, en las legislaciones de muchos países se establece una prohibición temporal (dos años, por ejemplo) de aceptar empleo en el sector privado, una vez abandonado el servicio público, cuando las organizaciones que ofrecen el empleo dependieron del funcionario correspondiente en decisiones o resoluciones de cualquier tipo. Este tipo de prohibiciones son muy importantes en las agencias reguladoras (como la Comisión Nacional del Mercado de Valores) donde las decisiones pueden tener efectos muy importantes sobre la cuenta de resultados de las empresas. Incluso, se puede prohibir al ex-responsable público, durante un periodo temporal, celebrar como empresario contratos con la Administración pública, en este caso para evitar un cierto tráfico de influencias.

1) Restricciones y control de nombramientos concurrentes fuera del gobierno. Un funcionario o responsable público puede, al tiempo que desarrolla su labor en la Administración, estar involucrado en puestos de responsabilidad en un partido político, o en una asociación legal de cualquier tipo como un ciudadano corriente. Obviamente, en estos casos, no se desarrolla normalmente la labor por razones lucrativas, sino por razones ideológicas, o por preocupaciones sociales, culturales o medioambientales. Sin embargo, la militancia política y/o social puede provocar conflictos de interés, de ahí que, para determinados puestos, se pueda exigir información relativa a este tipo de actividades cívicas y, en ocasiones, se pueda prohibir la ocupación de puestos de responsabilidad en este tipo de organizaciones o, incluso, la mera militancia. En general, podríamos distinguir cinco tipos de sujetos implicados en estas situaciones. En primer lugar, los funcionarios de nivel medio o inferior, los 
cuales no deben ser ni controlados ni perturbados en el ejercicio de estos derechos ciudadanos, pues no toman decisiones relevantes a estos efectos. No obstante, cuando sus informes puedan ser relevantes, y exista conflicto de interés, deberían optar por la abstención para ese caso concreto. En segundo lugar, los funcionarios profesionales de nivel superior, los cuales sí pueden tener restricciones en esta materia, al tomar decisiones o aportar informes relevantes. Por ejemplo, para funcionarios del Senior Executive Service, en los Estados Unidos y en otros países, se establece la prohibición de militancia partidista, dado que van a tener que trabajar como altos cargos para administraciones diferentes. En otros casos, lo que se prohíbe a altos funcionarios es ocupar puestos de responsabilidad en partidos políticos o en asociaciones que se relacionen con el cargo que se desempeña. En tercer lugar, están los miembros del gobierno y altos cargos, en los que la militancia partidista es parte normal y conveniente, en muchos casos, de su situación. Prohibir a presidentes, ministros o altos cargos pertenecer a partidos políticos es incoherente con la naturaleza de nuestras democracias, pero sí se les puede prohibir ocupar cargos relevantes en ONG's o asociaciones que se relacionen con las actividades propias del cargo. Cuarto, es la situación de los parlamentarios. Esta situación es parecida a la de los miembros del gobierno a estos efectos, no se puede prohibir la militancia partidista pero sí controlar su presencia en ONG's y asociaciones que tengan relación con la Comisión en la que desarrollan sus funciones. En algunos países, ciertos parlamentarios crean ONG's tapadera para recibir cuantiosas subvenciones y ayudas a través de un sistema corrupto de concesiones y subvenciones. Finalmente, los miembros del Poder Judicial, los cuales normalmente tienen y deben tener un sistema de incompatibilidad absoluta de pertenencia a partidos, sindicatos u ONG's.

m) Publicidad de las declaraciones de ingresos y patrimonio. De cara a facilitar el control social de los conflictos de intereses y a facilitar la lucha contra la corrupción, en determinadas legislaciones se establece la obligación de que, salvados los datos confidenciales, se publiciten, incluso en Internet, las declaraciones de bienes y patrimonio de los altos cargos del gobierno y funcionarios relevantes.

n) La regulación detallada de la obligación de abstención en la toma de decisiones o de la participación en reuniones de comités, cuando la participación o presencia del responsable público en dichos actos pudiere comprometer la necesaria imparcialidad del acto, dado el conflicto de interés directo o indirecto (por familiares o amigos cercanos) que el funcionario tiene en el mismo.

o) Restricciones en la propiedad de acciones y de empresas privadas. Cuando un alto cargo o un funcionario con responsabilidades, o sus familiares cercanos, posean acciones o sean propietarios de empresas que tengan relación con la Administración pública, el conflicto de intereses puede ser real o, en todo caso, es aparente. Para evitar tales conflictos, en muchos países se establece la prohibición de tener tales propiedades mientras se detenta el cargo, por lo que es obligatorio o renunciar al cargo o vender las acciones o empresas. Si se trata de miembros del gobierno o responsables de agencias reguladoras, también se les puede exigir que, si tienen acciones en cualquier tipo en empresas no contratistas con el sector 
público, durante su mandato procedan a contratar con una entidad financiera registrada la gestión de dichos valores, sin que puedan darles instrucciones de inversión durante tal periodo.

En definitiva, como se puede ver, el conflicto de intereses abarca un área de decisión y de regulación extraordinariamente amplia, pero no puede confundirse con la corrupción, pues aunque muchas veces coinciden, no siempre lo hacen.

\section{Razones para regular y gestionar} los conflictos de interés. Su integración en las estrategias de prevención y lucha contra la corrupción

\section{¿Por qué regular los conflictos de interés?}

Las actitudes públicas hacia la política, los políticos, los partidos políticos y los Parlamentos reflejan una creciente desconfianza. Los datos que indican que existe un divorcio entre políticos - y con ello de la política - y sociedad son numerosos, si buscamos en alguna de las más prestigiosas encuestas que han analizado este fenómeno empíricamente nos encontraremos con una sorprendente sintonía en las tendencias globales. Tomemos por ejemplo la Encuesta Mundial de Valores (World
VAlues SuRvey, WVS) y agreguemos los datos de las encuestas de 1981-82, 199091, 1995-96 y 1999-2000 - más de 280.000 encuestas para 81 países. En primer lugar, comparemos la importancia que se da a la política en comparación a otras variables de la vida social (ver Cuadro 1).

A continuación, analicemos la confianza que se otorga a los Parlamentos, gobiernos y partidos políticos en comparación con otros actores sociales (ver Cuadro 2).

En conjunto - aunque obviamente al ser encuestas globales las desviaciones estándar son elevadas y no en todos los países los datos son ni mucho menos similares -, ni los gobernantes actuales, ni los que pudieren surgir de los partidos de la oposición parecen generar confianza, de hecho, sólo un 3,7\% se manifestaba muy satisfecho con los gobernantes actuales de su país, y en la encuesta de 2000, un 58\% incluso preferiría que su país lo dirigieran expertos, no políticos. Consecuentemente, como quiera que los políticos no ofrecen confianza, el propio sistema político - necesariamente regido por políticos - tampoco la ofrece.

Toda esta argumentación tiene su confirmación regional en un reciente estudio del PNUD (2004) para Latinoamérica (ver Cuadro 3).

\section{Cuadro 1: Importancia otorgada a la política comparativamente*}

\begin{tabular}{|l|c|c|}
\hline Como de importante es: & $1981-1996$ & $1999-2000$ \\
\hline La familia & 85,5 & 89 \\
\hline Los amigos & 41 & 44 \\
\hline La diversión & 33,7 & 33 \\
\hline El trabajo & 62,7 & 65 \\
\hline La política & 11,6 & 11,8 \\
\hline
\end{tabular}

* Porcentaje de respuestas "muy importante" a la pregunta "cómo de importante es para su vida: la familia, los amigos, la diversión, el trabajo, la política".

Fuente: World Values Survey, 1981, 1990, 1995, 2000 y elaboración propia. 


\section{Cuadro 2: Confianza que inspiran los actores políticos en comparación con otros actores sociales*}

\begin{tabular}{|l|c|c|}
\hline Actores sociales & $1981-1996$ & $1999-2000$ \\
\hline La iglesia & 59,4 & 62,1 \\
\hline Las Fuerzas Armadas & 56,1 & 56,8 \\
\hline El sistema legal & 51,6 & $\mathrm{Na}$ \\
\hline La prensa & 43,0 & 41,8 \\
\hline La televisión & 46,2 & 31,4 \\
\hline Los sindicatos & 37,0 & 33,3 \\
\hline La policía & 53,9 & 53,0 \\
\hline El gobierno central & 41,2 & 28,9 \\
\hline El Parlamento & 41,9 & 37,6 \\
\hline El servicio civil & 44,0 & 40,3 \\
\hline Las empresas & 46,2 & 34,4 \\
\hline Los partidos políticos & 23,2 & 17,5 \\
\hline
\end{tabular}

* Suma de respuestas "gran o bastante" a la pregunta "cuanta confianza le ofrecen estas instituciones: la iglesia, las Fuerzas Armadas, el sistema legal, la prensa, la televisión, los sindicatos, la policía, el gobierno central, el Parlamento, el servicio civil, las empresas, los partidos".

Fuente: World Values Survey, 1981, 1990, 1995, 2000 y elaboración propia.

\section{Cuadro 3: Índice de confianza en instituciones en América Latina*}

Índice de confianza en instituciones

\begin{tabular}{|c|c|c|c|c|}
\hline Poder judicial & Gobierno & Municipios & Congreso & Índice \\
\hline 1,96 & 1,93 & 2,12 & 1,88 & 1,97 \\
\hline
\end{tabular}

Índice de confianza en actores

\begin{tabular}{|c|c|c|}
\hline Gente que dirige el país & Partidos políticos & Índice \\
\hline 2,12 & 1,61 & 1,86 \\
\hline
\end{tabular}

* Al consultar a las personas el grado de confianza que tienen en cada una de las instituciones y actores que se mencionan, éstas pueden responder "Ninguna", "Poca", "Algo" y "Mucha". A cada una de estas alternativas se les asigna valores de 1 a 4, respectivamente. Se calculó la confianza promedio de manera que entre más cercano a cuatro sea ese promedio, mayor será la confianza de los entrevistados en ese rubro. Para el cálculo de estos índices se suma el valor de las respuestas dadas a las preguntas que intervienen en el índice y se divide entre el número de preguntas, obteniendo así un promedio simple.

Fuente: Procesamiento de preguntas p17st, p34st y p36st del Latinobarómetro 2002 realizada por PNUD (2004). 
Si nos preguntáramos por el por qué de estos datos, la respuesta tiene que ver, sobre todo, con el comportamiento de la clase política. Son, esencialmente, factores de rendimiento de la clase política los que explican este deterioro, y, dentro de los factores de rendimiento es, sobre todo, la corrupción y la consiguiente quiebra de fidelidad entre representantes y representados la que explica en gran medida la desafección y la falta de confianza (DeLLA Porta, 2000; Pharr, 2000).

Como muestra de ello, si analizamos los países europeos incluidos en el presente informe veremos que la imagen de las instituciones y de la propia democracia sufre ante esta generalizada percepción de corrupción política. No obstante, es cierto que, además, cuando la corrupción en sentido estricto - sobornos, cohechos, etc. - también es alta, el deterioro es aún mayor.

La ciudadanía en general - sobre todo en países con poliarquías estables - tiene una idea bastante clara sobre el fin de la política y del Estado, sobre su razón de ser, y tanto en un ámbito - la política como en el otro - el Estado - los partidos políticos y sus representantes son los actores privilegiados en ambas arenas, de ahí que esos actores deban conformar su acción de acuerdo a la imagen que la ciudadanía tiene del "deber ser" de la política y del Estado. Y en ese "deber ser" la esencia está en la búsqueda del interés común respetando las reglas del juego político. Pues bien, es precisamente la percepción de que

Cuadro 4: Confianza en el Parlamento, satisfacción con el funcionamiento de la democracia y puntuación en el Índice de Percepción de Corrupción (CPI) en diez países de la Unión Europea

\begin{tabular}{|l|c|c|c|}
\hline País & $\begin{array}{c}\text { Mucha o bastante } \\
\text { confianza en el } \\
\text { Parlamento } \%\end{array}$ & $\begin{array}{c}\text { Muy satisfecho o } \\
\text { bastante satisfecho } \\
\text { con el funcionamiento } \\
\text { de la democracia en } \\
\text { mi país } \%\end{array}$ & $\begin{array}{c}\text { CPI 2005 (cuanto } \\
\text { más cercano a } \\
10 \text { menor corrupción) }\end{array}$ \\
\hline Nuevos UE & 26,3 & 28,2 & 4,2 \\
\hline Letonia & 30,1 & 40,6 & 3,4 \\
\hline Polonia & 32,6 & 31,6 & 5,0 \\
\hline Hungría & 12,0 & 36,6 & 4,3 \\
\hline Rep. Checa & & 44,4 & 8,6 \\
\hline Antiguos UE & 34,1 & 72,8 & 8,2 \\
\hline Gran Bretaña & 34,2 & 45,5 & 7,5 \\
\hline Alemania & 38,8 & 63,2 & 7,0 \\
\hline Francia & 45,0 & 72,3 & 6,5 \\
\hline España & 43,7 & 34,6 & 5,0 \\
\hline Portugal & 33,2 & & \\
\hline Italia & & & \\
\hline
\end{tabular}

Fuente: World Values Survey, 2000 and CPI 2005 (Transparency International). 
los políticos no buscan el interés general lo que lleva a la desconfianza, es la percepción de que no tratan todas las preferencias por igual en la conducción del Estado - uno de los requisitos esenciales de la democracia - y/o de que en sus decisiones la búsqueda del poder prima sobre la búsqueda del bien común lo que deteriora las relaciones. Por ejemplo, en el Latinobarómetro de 2003, al preguntarse sobre el factor más importante para confiar en las instituciones públicas, se encontró como respuesta mayoritaria: "el trato a todos por igual"; de ahí que la ciudadanía demande un aparato del Estado al servicio de todos y no cooptado (KLIKSBERG, 2005, p. 83). En suma, es la corrupción de la política lo que genera esta separación entre representantes y representados, corrupción que incluye todo el conjunto de acciones políticas en que los partidos y sus representantes se embarcan rompiendo las reglas del juego - clientelismo, compra de votos, financiación fraudulenta...- así como todos aquellos otros en los que anteponen el interés privado sobre el general - captura de políticas, abuso de poder, venta de decisiones, nepotismo...

Un último dato para demostrar la percepción ciudadana sobre la corrupción política: según la WVS, en 1990, ante la pregunta " ¿Hablando en general, usted diría que este país es dirigido por unos pocos grandes intereses preocupados sólo por ellos mismos o es dirigido en interés de toda la gente?", el 55\% de los encuestados respondían que por unos pocos grandes intereses, pero en 2000 dicha respuesta subió a un $67 \%$, incluidas en esa tendencia casi todas las poliarquías consolidadas. La ciudadanía parece tener cada vez más claro que la política se está pervirtiendo, que existe un problema con la necesaria inclusividad propia de toda democracia, pues los actores políticos se oligarquizan y olvidan el interés común. No es sólo un problema de sobornos y tráfico de influencias, el fenómeno es mucho más complejo. De ahí que se desconfíe de los actores políticos incluso en países de bajísima corrupción en sentido estricto. Por supuesto que la situación en Bolivia no es la misma que en Dinamarca, y que no todos los políticos actúan igual, pero las tendencias globales van en la misma dirección porque la corrupción política sobrepasa la mera "mordida".

De ahí que sea importante recordar la definición que dimos anteriormente de corrupción y dejar claro que la corrupción no se limita al soborno, sino que también incluye todos aquellos supuestos en los que sin soborno y sin delito se priorizan los intereses privados sobre el interés general. $\mathrm{Y}$ es aquí donde aparece el conflicto de intereses como fuente esencial de corrupción. Por ello, para luchar contra la corrupción y prevenir su surgimiento se hace indispensable gestionar adecuadamente los conflictos de interés y tratar de evitar, en la medida de lo posible, su existencia.

\section{Lucha contra la corrupción y políticas de gestión de los conflictos de interés}

Como consecuencia de todo lo anteriormente indicado, sería inteligente considerar la prevención y regulación de los conflictos de interés como parte de una estrategia global de prevención y lucha contra la corrupción, y no como una pieza separada de tal política global. Por ello, situadas en ese contexto, las medidas para gestionar los conflictos de interés son un instrumento importante para generar integridad en el sector público y para defender y promover una mejor y más legitimada democracia. 
No hay que olvidar que la corrupción no solamente genera una mala imagen para los políticos y las instituciones democráticas, sino que, además, provoca enormes daños institucionales y para el desarrollo de los países. Así, desde una perspectiva política, reduce la calidad de la democracia y del rendimiento gubernamental, creando un capital social negativo (LeVI, 1996). Cuando la corrupción es elevada no existe igualdad jurídica real, al contrario, el tratamiento preferencial para las personas integradas en las redes de corrupción que detentan el poder es la regla. En países altamente corruptos, los políticos y los funcionarios tienen un interés racional en que la Administración funcione ineficientemente, porque gracias a tal ineficiencia ellos pueden ofrecer selectivamente protección a sus clientes frente a tales ineficiencias, obteniendo con ello beneficios extraordinarios. La corrupción, además, exige confianza entre los actores que toman parte en los intercambios ilegales o inmorales, esta confianza favorece la expansión de densas redes sociales de apoyo mutuo, pero estas redes son sinónimo de clientelismo y soborno (Della Porta; Vanucci, 1997). La corrupción política reproduce y fortalece esas redes, redes de capital social negativo.

Desde una perspectiva económica, la corrupción genera todo un conjunto de daños que pueden resumirse en los siguientes (TANZI y Davoodi, 2001; Kauffman, KraAy y Zoido-Lobatón, 1999, 2000):

1) Incrementa la inversión pública pero reduce su productividad; así, si la corrupción de Singapur ascendiera a la de Pakistán, ello incrementaría el gasto público como porcentaje del PIB en 1.6 puntos y reduciría los ingresos públicos sobre PIB en diez puntos porcentuales. En otro ejemplo, tras los procesos italianos de Mani Pulite, en
Milán los costes por kilómetro en línea de metro cayeron un $57 \%$, y la construcción de la terminal del nuevo aeropuerto redujo sus costes en un $59 \%$.

2) Incrementa los gastos corrientes vinculados a políticas improductivas, aumentando el gasto público ineficiente; por ejemplo, ordenadores en lugares que apenas tienen luz eléctrica o equipos médicos muy sofisticados en hospitales que carecen de lo elemental.

3) Reduce la calidad de las infraestructuras existentes, pues el rápido deterioro favorece la repetición del negocio; así ocurre que las carreteras en países altamente corruptos están continuamente reparándose, con lo que el funcionario percibe comisión por cada contrato de reparación y el empresario corruptor se ahorra costes con la baja calidad de los productos usados. También fallan servicios públicos esenciales - agua, electricidad, etc. - dados los desincentivos para invertir en un adecuado mantenimiento de las infraestructuras y redes precisas para el servicio, pues la tendencia es a sacar el máximo beneficio mientras se conoce al funcionario o político correspondiente, y a evitar hacer previsiones a largo plazo, dados los cambios políticos y los posibles cambios en las redes de corrupción con la llegada de nuevos gobiernos.

4) Disminuye los ingresos del Gobierno, pues favorece el dinero negro, el contrabando y la evasión fiscal. Además de obligar a esfuerzos importantes en el blanqueo de capitales, con los consiguientes costes de oportunidad. Los costes de oportunidad a que lleva la corrupción son elevados, pues se ha de emplear bastante tiempo en ocultar datos, gestionar la información, lavar dinero, etc.

5) Actúa como un impuesto arbitrario, especialmente cuando la corrupción no está 
centralizada. Los actores económicos no saben muy bien cuánto les va a costar cada transacción y tampoco tienen asegurada la contraprestación cuando el negocio está muy fragmentado.

6) Distorsiona los incentivos y produce una selección adversa de élites, los más capaces y de más talento se dedican a la "búsqueda de rentas" en lugar de a la actividad productiva.

7) Reduce la capacidad del gobierno de imponer controles regulatorios e inspecciones para corregir los fallos de mercado. Es corriente escuchar en numerosos países latinoamericanos quejas ciudadanas sobre el comportamiento de empresas - muchas veces españolas - que tras las privatizaciones se han quedado con el monopolio u oligopolio de mercados de red, antes operados por empresas públicas, sin que los entes reguladores actúen ante las denuncias, dada la captura por esas empresas de los entes y los gobiernos que los dirigen. En Jamaica, por ejemplo, las pérdidas y mal funcionamiento de la compañía de aguas de la capital se debían en gran medida al soborno a los inspectores por parte de las personas y empresas más poderosas y al deficiente mantenimiento de la red, muchas veces voluntariamente consentido para poder justificar la discrecionalidad en el cobro de los precios.

8) Distorsiona el papel del Estado como garante de derechos de propiedad o asegurador del cumplimiento de los contratos. Aquí la corrupción judicial es fundamental para explicarse esta degradación del papel del Estado. La corrupción judicial destruye la seguridad jurídica y crea un clima de arbitrariedad que impide toda previsibilidad y estrategia económica a medio y largo plazo. Lo mismo ocurre con un sistema corrupto de registro de propiedad o fe pública en los contratos. Los datos sobre corrupción judicial precisamente han empeorado en los países de la OCDE en los últimos seis años (Kauffman, 2005).

9) Reduce la inversión y, por ello, la tasa de crecimiento. Si Filipinas redujera su corrupción a la de Singapur, incrementaría la inversión como porcentaje del PIB en 6.6 puntos porcentuales.

10) Reduce los gastos en educación y salud, por ser áreas donde es más difícil obtener grandes beneficios, y aumenta los gastos militares, por ser una partida de gasto donde los beneficios por soborno son muy altos.

11) Reduce la inversión extranjera directa, pues la corrupción opera como un impuesto a las empresas. De hecho, si a Singapur le aplicáramos el nivel de corrupción de México sería como incrementarle el tipo impositivo marginal sobre las empresas en 20 puntos porcentuales.

Socialmente, promociona la desigualdad psicológica y económica y expande confianza particularista y parroquial, es decir, aquella que se da solamente en el interior de redes clientelistas (Rothstein; UsLaner, 2005). La confianza particularista impide la generación de confianza generalizada e inclusiva, es decir, aquella que se expande entre todos los miembros de una sociedad. Precisamente, la confianza generalizada es el tipo de confianza esencial para la solidaridad social, el pago voluntario de impuestos y la formulación y ejecución equitativa de políticas públicas.

Resumiendo, la insatisfacción ciudadana con el funcionamiento de los partidos políticos y de los gobernantes por razones de falta de preocupación suficiente por el interés general se traslada rápidamente a su insatisfacción con el funcionamiento de 
la propia democracia y a la expansión de una desconfianza hacia las instituciones y la propia ciudadanía que pone en riesgo la gobernabilidad democrática y el desarrollo económico y social.

Dados todos estos factores, todos los países deben tener una política que prevenga y combata la corrupción, incluso cuando la corrupción percibida y real en el país correspondiente sea baja. Pues la inacción en este campo produce la rápida expansión del fenómeno ante los grandes beneficios que se obtienen y las expectativas de impunidad. Dentro de estas amplias políticas, las políticas específicas para gestionar los conflictos de interés juegan un papel relevante. Veamos cómo se sitúan.

La lucha contra la corrupción exige, si quiere tener éxito, medidas estructurales, medidas preventivas, medidas vinculadas a la detección e investigación de conductas corruptas y medidas sancionadoras eficaces (RAILE, 2004).

1) Las medidas estructurales tienen que ver fundamentalmente con la lucha contra la desigualdad, pues la desigualdad es una variable que correlaciona a grandes rasgos con la corrupción, pero también, vinculado a ello, con la preocupación permanente por formular e implantar políticas educativas a todos los niveles que fomenten la conciencia cívica y expandan el compromiso con la ética pública. Todo ello sin olvidar el necesario fortalecimiento del capital social positivo, apoyando para esto todo lo que pueda contribuir a generar una sociedad civil activa y vigilante, densamente poblada de acuerdos y compromisos cívicos y comerciales. Políticamente, desde una perspectiva estructural, una lucha contra la corrupción exige una preocupación por la construcción de una democracia de calidad, una democracia donde existan elecciones libres y justas, un gobierno abierto y que rinda cuentas, derechos civiles, políticos y sociales garantizados y una sociedad civil democrática, donde las asociaciones estén sometidas también a reglas democráticas, donde los medios de comunicación sean accesibles a los diferentes grupos sociales e informen libre y objetivamente, donde las grandes corporaciones privadas tengan políticas de responsabilidad social, donde la cultura política y el sistema educativo tengan un carácter democrático, etc. (BётнAм, 1994).

2) Las medidas preventivas, que se deducen de las estructurales, se centran en fortalecer los instrumentos internos de control y democracia de los partidos, el desarrollo de códigos éticos en los partidos, en el Gobierno y en la Administración, y en la formación en ética pública y democracia a dichos actores: partidos y empleados públicos. Desde una perspectiva institucional, la prevención incluye tener un marco normativo que desincentive la corrupción, con normas penales actualizadas, normas que aseguren la concurrencia de ofertas y la transparencia en las contrataciones públicas, normas disciplinarias sencillas y eficaces, normas reguladoras de los conflictos de interés e incompatibilidades coordinadas y sin lagunas, etc. Desde luego que, además, la prevención está vinculada a asegurar un servicio civil meritocrático, suficientemente remunerado y eficaz, socializado en los valores del servicio público. Y una Administración que rinde cuentas ante los ciudadanos a través de mecanismos como las leyes de acceso a la información, las cartas de servicios, la Administración electrónica, los presupuestos participativos, los "ombudsman", la información sobre patrimonio e ingresos de los cargos públicos, etc.

3) Instrumentos de detección e investigación. No obstante, a pesar de la importancia de todo lo anterior, una adecuada 
política anticorrupción requiere que existan instrumentos institucionales de detección e investigación de las actividades sospechosas que permitan, en su caso, la acusación de corrupción y la sanción correspondiente. Para ello, se deben incorporar instrumentos como los que siguen:

- Un sistema de denuncias de corrupción y fraude abierto, sencillo y riguroso, que fomente la denuncia sólida y desincentive la denuncia de mala fe.

- Un sistema de protección al denunciante veraz, que evite y sancione las represalias y persecuciones a quien actuó con civismo.

- Una controladuría e inspección especializada, coordinada con los servicios tributarios y que tenga acceso a los datos bancarios.

- Una fiscalía (procuraduría) especializada y con un grado suficiente de independencia.

- Jueces especializados en delitos económicos y de corrupción.

- Un sistema de órganos de control contable, económico y financiero coordinados, profesionales y bien dotados.

- Un acceso a los datos fiscales por los órganos de control.

- Un órgano de impulso y monitoreo del sistema.

4) Instrumentos de penalización y sanción efectivos y que se cumplen. Finalmente, cuando los datos surgidos de la investigación permitan concluir que ha existido un acto corrupto, fraudulento o inmoral, es preciso que los instrumentos de sanción operen y se evite la impunidad. Ello requiere un sistema penal efectivo, que asegure castigos para los servidores públicos que han incurrido en delitos o faltas. Un sistema, además, que sea capaz de recuperar los fondos robados al país y evite el lavado de capitales obtenidos de forma delictiva.
Un sistema disciplinario, para los supuestos menos graves, que también sea eficaz y real. Un sistema de responsabilización económica por los daños patrimoniales causados a la hacienda pública que asegure la restitución del daño. Y, finalmente, un sistema de sanciones administrativas y morales que asegure que los responsables públicos que actuaron indebidamente son, al menos, sancionados con el cese, la publicación en diario oficial de su acción, etc.

Hecho este mapa de acciones y estrategias anticorrupción, se puede asegurar que la gestión de los conflictos de interés está presente en las cuatro grandes áreas antes mencionadas. Es parte del marco estructural, porque estas políticas ayudan al sistema democrático a generar confianza en las instituciones y abren el gobierno al escrutinio ciudadano. Forman parte esencial de las acciones preventivas, dado que las normas sobre incompatibilidades y conflictos de interés, los códigos de conducta y las normas sobre abstención constituyen un elemento central en la arquitectura preventiva del sistema. Está inserta en la dimensión investigadora de la corrupción, porque algunos de sus instrumentos, como las declaraciones de ingresos y patrimonio personal y familiar aportan elementos importantes para la labor de detección de corrupción. Y, finalmente, forma parte de la actividad represora y sancionadora, dado que, en algunos países, el incumplimiento de las normas de conflictos de interés implica un delito y, en casi todos los países, tales incumplimientos llevan aparejadas sanciones administrativas de muy diverso tipo.

\section{Políticas públicas y conflictos de interés}

En las páginas que siguen se va a intentar definir el tipo de políticas que 
estudiamos, su forma de introducirse en la agenda gubernamental, su lógica interna y las peculiaridades de su expansión y desarrollo

El conjunto de programas y decisiones relacionadas con los conflictos de interés en los países estudiados se sitúa en el marco de las políticas públicas que buscan prevenir y combatir la corrupción. Este tipo de políticas relacionadas con los conflictos de interés son, si hubiera que definirlas, políticas constitucionales, es decir, políticas que tienen que ver con las reglas del juego político (Lowi, 1972) y que intentan establecer una protección institucional frente a patologías inherentes a la acción política y administrativa, en esencia: el abuso de poder para beneficio privado directo $\mathrm{o}$ indirecto. Como tales, son políticas que se juegan en arenas bastante centralizadas, muchas veces sus debates no salen de círculos muy reducidos de especialistas y profesionales de la política. Este estudio no incorpora un análisis detallado de los procesos, pero en la investigación sí se ha podido comprobar el carácter centralizado y tecnocrático de los debates e interacciones que este tipo de políticas conlleva. Pocos actores, poco debate abierto, pero mucho juego subterráneo en las fases de redacción de normas e implantación de las mismas.

John Kingdon, en su multicitada obra Agendas, Alternatives and Public Policies (1995), basándose en la teoría del "garbage can", nos indica que para que un problema socialmente relevante dé lugar a una política pública gubernamentalmente asumida debe producirse una confluencia de corrientes que abran "una ventana de oportunidad". Hay sucesos que pueden generar un movimiento de las corrientes y, como consecuencia de ello, su encuentro en un punto dado, lo que genera la apertura de posibilidades para que se resuelva el problema correspondiente. Las tres corrientes, que tienen vida propia y que pueden o no confluir, son: la corriente de los problemas, la corriente de la política y sus juegos de interés y poder, y la corriente de las políticas con las soluciones técnicas correspondientes.

Esa ventana no permanece abierta mucho tiempo, si quienes están interesados en usarla no actúan rápido otro problema llegará a ocupar ese espacio. Las ventanas se cierran si nuevos acontecimientos ocupan todo el marco y no se ha sido suficientemente ágil para abordar el problema anterior. También se cierran si se consideran medidas que parece que lo van a resolver pero no se adoptan decisiones, es decir, si nos encontramos con actores que "sienten" que el problema se aborda pero no generan verdaderas respuestas institucionales. $\mathrm{La}$ ventana se cierra, también, si hay un cambio de los actores clave y no se generan recambios inmediatos. $\mathrm{O}$, finalmente, $\mathrm{y}$ sin ánimo de exhaustividad, si hay un fracaso en las primeras decisiones. El estudio de los nueve casos nos indica que aunque las normas se hayan aprobado en todos los países estudiados, la ventana se cerró en muchos de ellos sin que realmente llegara a adoptarse la política con todas sus consecuencias.

Por otra parte, el análisis de estas políticas y programas nos muestran un hecho sorprendente, a primera vista, y es que estas reformas surgen, en ocasiones, sin "problema" previo, es decir, que no han existido grandes escándalos de corrupción que generen una conciencia social que impulse las reformas. En otras ocasiones, sí se ha producido ese escándalo y ha sido un elemento a considerar. Finalmente, hay países en los que la corrupción está muy asentada y ya no produce, salvo momentos puntuales, escándalos, sino un continuo 
flujo de informaciones que asientan un estado de opinión fuertemente cínico y descreído sobre la política y los políticos, donde "ya nada sorprende". En resumen, el "problema" no ha sido elemento insustituible en el origen de estas políticas.

Sin embargo, últimamente, las políticas han estado a disposición de los actores de forma continua. El conjunto de soluciones listas para ser usadas, las respuestas técnicas en busca de problemas que solucionar (March; Olsen, 1989) han sido desde hace algunos años una permanente fuente de impulso reformador en este área. Finalmente, la política siempre ha sido un componente clave para el impulso definitivo de los programas estudiados. $\mathrm{O}$ bien porque la adhesión a la Unión Europea era el objetivo clave de los gobiernos y estas reglas eran parte del paquete a asumir. $\mathrm{O}$ bien porque algún escándalo hacía necesaria la relegitimación a través de medidas simbólicas de este tipo. O bien porque actores relevantes consiguieron generar una “advocacy coalition" suficientemente poderosa en torno a la idea del buen gobierno que la coalición contraria no consiguió parar (SABATIER, 1999). En cualquier caso, el éxito en la introducción en la agenda gubernamental de la política no exime de las tensiones implantadoras, de ahí que sólo cuando ha existido una coalición promotora suficientemente fuerte y que se ha mantenido unida la implantación ha tenido éxito mientras que, en el resto de los casos, las implantaciones han sufrido los tradicionales retrasos y fracasos, con la consiguiente desnaturalización de la política originalmente planteada.

En todo caso, y subrayando la importancia del "path dependency", hay que reconocer que aun cuando el nivel de corrupción influye en la mayor "facilidad" con que se construye una coalición en torno a la idea de "un buen gobierno", también es cierto que esa mayor corrupción hace mucho más difícil la redacción de normas sin "trampa" y, sin lugar a dudas, hace mucho más trabajosa e ineficaz la implantación de las medidas tomadas, sobre todo considerando que dichas medidas ya surgen lastradas por intereses que buscan su fracaso.

Dicho esto, la cuestión, ahora, es la de definir la lógica que existe tras la difícil y, muchas veces, precaria existencia de estas normas sobre conflictos de interés. El reciente premio Nóbel de economía Thomas Schelling, al estudiar las inconsistencias con las que los seres humanos actuamos, especialmente en relación a nuestras dificultades para diferir la gratificación y la recompensa, ha acuñado el término "lucha íntima por el autocontrol", un término con el que nos explica que la razón de las inconsistencias en nuestro actuar se debe a que las personas nos comportamos como si dos personas distintas fueran las que tomaran las decisiones en un momento y en otro, en el momento en el que fríamente pensamos en lo que debemos hacer y en el momento en el que tenemos que hacerlo (ScHELLING, 1984). A nuestros efectos, habría, dentro del mismo líder político, dos personas distintas actuando cuando toma decisiones. Es una persona racional y patriota cuando desde la oposición o en campaña electoral decide impulsar las normas sobre conflictos de interés, y es otra cuando ya en el poder se enfrenta a ser coherente con la decisión tomada y, en consecuencia, a diferir o rechazar los beneficios personales de usar las instituciones públicas para fines partidistas o personales, auque sepa que tal abuso daña al país y deslegitima la política. La primera persona actúa racionalmente, considerando lo mejor para el país. La 
segunda actúa egoístamente, considerando lo mejor para sí: bien sea reforzar apoyos, comprar voluntades o, simplemente, evitar los conflictos internos dentro de su red política de apoyo. Una red que, muy a menudo, rechaza estas medidas al considerarse excesivamente perjudicados por estas normas que les obligan a ser más transparentes y les ponen fácilmente en el punto de mira de la prensa y de la oposición.

La dificultad que existe para formular e implantar estas políticas tiene que ver con este conflicto interno no sólo en la mente de cada actor político, sino entre unos actores políticos que representan la racionalidad y el deber ser y otro conjunto de actores que representan el interés egoísta y a corto plazo. Estos últimos no pueden hacer explícito su mensaje de fondo, de ahí que su retórica se fundamente en los costes económicos de las medidas, en la dificultad que las medidas generan para captar políticos de valía en el sector privado, o en la irresponsabilidad de la prensa y la oposición y su tendencia a abusar de estas normas y prácticas para fines egoístas. Por su parte, los partidarios de estas políticas tratan de conseguir evitar que la visión cortoplacista devore a la visión a largo plazo, o que, en última instancia, el clientelismo, el patrimonialismo y, sobre todo, la corrupción sustituya al buen gobierno democrático. Pero tienen un grave problema para triunfar: este tipo de políticas generan beneficios difusos pero costes concentrados (Gomá; Subirats, 1998). Los "outcomes" son muy difíciles de prever y evaluar, en todo caso lo son a largo plazo y, además, las políticas preventivas en esta materia tienen éxito porque no se generan escándalos, pero al no generarse escándalos no se ven claramente sus efectos.
Finalmente, los costes son muy visibles: engorrosos formularios, oficinas de control, sensación de vigilancia, "red tape", uso demagógico por la prensa o la oposición de la información...

Cuando la coalición contraria a esta política domina el escenario nos encontramos con un grave problema de trampa social. Porque si los actores implicados en tal irracionalidad fueran ciudadanos normales, el Estado podría usarse para

$\quad$ "La lucha
contra la corrupción
exige, si quiere
tener éxito, medidas
estructurales,
preventivas,
vinculadas
a la detección e
investigación de
conductas corruptas
y medidas
sancionadas
eficaces."

ayudarles en su toma de decisiones racionales, incluso sin necesidad de imponerles nada, simplemente impulsando de forma paternal su voluntad inicial de actuar racionalmente, con paternalismo libertario (Susstein; thaler, 2003). Como se hace con los jugadores compulsivos en ciertos Estados norteamericanos. Pero ¿cómo guiar decisiones correctas y racionales de los actores cuando es el propio 
Estado, a través de sus representantes, el que opta por la irracionalidad? Bien, en ese caso, sólo cabría una coerción externa.

Entre los países estudiados, se podría decir que existen dos grandes grupos, por una parte, aquellos que para ingresar en la Unión Europea han tenido que incorporar a su ordenamiento políticas de conflicto de interés que alcanzaran un mínimo de calidad y coherencia, y aquellos otros que estando ya dentro han ajustado sus políticas de conflicto de interés a las nuevas realidades del país y a los avances de otros países en la regulación de las mismas, avances conocidos sobre todo gracias a la OCDE. Lo cierto es que existen múltiples similitudes que expresan tendencias al acercamiento de enfoques y regulaciones. El fundamento de estas tendencias, además de las facilidades que generan las nuevas tecnologías para la globalización de la información y la rapidez de la comunicación, es la tendencia isomórfica de las organizaciones.

Según la teoría del isomorfismo institucional (Dimaggio; Powell, 1983), las organizaciones funcionan en retículos o campos interorganizativos, en los que se agrupan por entornos de referencia, desde esa perspectiva, las organizaciones públicas pertenecerían a un mismo retículo. En esos campos, la tendencia de las organizaciones es a adoptar arreglos y reglas institucionales consolidadas Las organizaciones que, como las Administraciones impulsoras de las reformas en los nuevos países miembros de la UE, inician un proceso de estructuración, tienen que afrontar un conjunto de situaciones nuevas y, ante ello, recurren a soluciones que ya se conocen y han tenido éxito en el retículo al que pertenecen.

$\mathrm{El}$ isomorfismo tiene a incrementarse cuanto mayor es el grado de institucionalización del campo interorganizativo. En muchos países, como consecuencia de la presión de la burocracia central existe un isomorfismo coercitivo, en programas de regulación de conflictos de interés, para con las Administraciones locales. Pero también las organizaciones centrales sufren la coerción por parte de los organismos multilaterales que actúan como promotores de políticas que entienden como necesariamente generalizables. Por otra parte, debido a la transferencia de consultores pagados por los propios organismos multilaterales, y a la profesionalización cada vez mayor del personal propio, existe presión normativa, es decir, un conjunto de métodos, condiciones de trabajo, sistemas de legitimación del rendimiento o criterios cognitivos ya legitimados que los burócratas de las Administraciones - por áreas y profesiones - tratan de incorporar a sus instituciones de destino. En este campo de la prevención de la corrupción ambos tipos de isomorfismos coercitivo y normativo - operan y explican, en gran medida, los programas de regulación de conflictos de interés establecidos. Con una diferencia, en los nuevos países miembros esta incorporación de regulación ha tenido un carácter fuertemente coercitivo, pues era parte de los requisitos de la adhesión, mientras que en los antiguos países miembros la nueva regulación es mayormente consecuencia de una cierta normatividad o deber ser que se sitúa en los órganos horizontales del gobierno y que da origen al movimiento de reforma. Las consecuencias sobre la implantación de este diverso origen no son menores, pues las políticas impuestas son más difícilmente implantables, al no considerar a menudo el déficit institucional y cultural existente. En última instancia, estas políticas encajan perfectamente en sociedades dominadas por valores postmaterialistas, pero no tanto en sociedades con valores de subsistencia (INGLEHART, 1998). 
Veamos, ahora, los elementos comunes y diferenciales de cada país en estas políticas.

Puntos comunes y diferencias en las estructuras, métodos y procesos utilizados para gestionar los conflictos de interés en Europa

En esta parte del informe, se procederá a resumir las principales diferencias y puntos en común de los instrumentos y procesos utilizados para gestionar los conflictos de interés en los nueve países estudiados. Para ello, seguiremos un itinerario consistente en comenzar por describir cómo se sitúan las políticas de gestión de conflictos de interés en las estrategias globales de lucha contra la corrupción, continuando por una revisión de sus normas y prácticas en cada una de las diferentes medidas normalmente utilizadas para gestionar tales conflictos y, finalmente, se procederá a describir los diferentes enfoques de detección, investigación, persecución y sanción de los incumplimientos a la normativa vigente en cada Estado. Al tiempo, se intentarán describir las diferencias fundamentales en los enfoques de los países estudiados.

Presencia o ausencia de políticas globales de prevención y lucha contra la corrupción

Todos los países recién ingresados a la Unión Europea y aquí estudiados tienen una amplia estrategia de lucha contra la corrupción, y la normativa sobre conflictos de interés forma parte de esa estrategia global. Sin embargo, los países antiguos miembros no tienen esas estrategias globales al menos de forma explícita. Sólo Alemania tiene un acuerdo federal de lucha contra la corrupción, un acuerdo que no tiene la característica de una política pública expresamente diseñada y detallada, pero que cumple un papel de definición global de objetivos. El Reino Unido ha adoptado un enfoque positivo, en lugar de un enfoque represivo, y ha establecido una política global de promoción de los estándares éticos en la vida pública, en el marco de esta política sí podrían situarse las políticas de gestión de los conflictos de interés.

\section{Medidas de regulación adoptadas en cada país}

Para cada país se han analizado las normas existentes que afectan a: miembros del Gobierno, cargos de nombramiento político o altos cargos, funcionarios, jueces, parlamentarios, electos locales.

\section{Restricciones en empleo adicional al empleo público}

En general, todos los países tienen fuertes restricciones con empleo adicional para:

- Miembros del gobierno

- Nombramientos políticos

- Funcionarios

- Jueces

Los miembros del gobierno y nombramientos políticos tienen, en general, unas incompatibilidades casi absolutas con cualquier otro puesto público o privado ${ }^{2}$. Los comisarios de la Unión Europea no pueden ni cobrar los derechos de autor por libros publicados durante su mandato y que tengan relación con su actividad. Los jueces también tienen un sistema de incompatibilidades absoluto. Pero para los funcionarios sí existen algunas diferencias por países y el sistema puede ser más o menos exigente. En Polonia, Alemania, Francia y España estas restricciones con empleo adicional son más rigurosas.

En todos los países, cuando los electos trabajan a tiempo completo y reciben remuneración pública tienen restricciones 
con empleo público y privado. En concreto, los miembros del Parlamento tienen restricciones con otro empleo público en casi todos los países. No obstante, los electos locales pueden ser diputados en Francia y Hungría; en España, las normas que impiden esta compatibilidad son normas internas de los partidos. Cuestión diferente es con el empleo en el sector privado o el ejercicio profesional. Así, en los países nuevos miembros se admite una cierta compatibilidad con el sector privado - siempre que los intereses privados no sean incompatibles con los públicos - dados los bajos salarios a abonar a los parlamentarios. En general, sólo España tiene estrictas incompatibilidades con todo tipo de puestos privados, otros países tienen incompatibilidades con ciertos puestos privados, especialmente los que comprometan la independencia, pero para el resto son más flexibles (por ejemplo, el Reino Unido).

\section{Declaración de ingresos personales:}

Esta declaración no es precisa en Francia, Alemania y Reino Unido para ningún responsable público. No obstante, en Alemania y Reino Unido, los miembros del Parlamento deben declarar ciertos ingresos si la suma es importante.

En Hungría e Italia sólo los miembros del Parlamento deben declarar con carácter general los ingresos. No obstante, ahora en Italia también los altos cargos en ciertos casos deben declarar sus ingresos.

En Polonia los altos cargos y los electos locales deben declarar sus ingresos, pero no el resto.

En España los altos cargos deben declarar sus ingresos al tomar posesión y anualmente. Los electos locales y parlamentarios sólo lo declaran al tomar posesión del cargo, cuando declaran sus actividades e intereses.
En Letonia, además de los electos y altos cargos, los funcionarios también tienen la obligación de declarar sus ingresos, de forma semejante a las obligaciones existentes en Brasil en esta materia.

\section{Declaración de ingresos familiares}

Esta declaración no es obligatoria en ningún país excepto en Polonia para las esposas/os de altos cargos y electos locales. La peculiaridad polaca está vinculada a la preocupación por la corrupción en el ámbito local, que es muy elevada.

En España, esta declaración es voluntaria para las esposas/os de altos cargos.

\section{Declaración de patrimonio personal}

En general, los miembros del gobierno, altos cargos, electos locales y parlamentarios sí deben declarar su patrimonio al inicio del cargo y al final del mismo. Sin embargo, no es precisa en Alemania y Reino Unido aunque los miembros del Parlamento británico deben declarar su patrimonio cuando éste se sitúa por encima de las 60.000 libras esterlinas. Y los parlamentarios alemanes deben declarar formalmente, antes de tomar posesión, que no tienen altos niveles de endeudamiento personal.

En los países antiguos miembros de la Unión los funcionarios no tienen que declarar patrimonio, al igual que no declaran ingresos. En los tres nuevos sí declaran patrimonio, aunque en Hungría esta obligación sólo afecta a los funcionarios de mayor nivel.

\section{Declaración de patrimonio familiar}

En ningún país estudiado los familiares de los responsables públicos deben declarar, excepto en:

- Polonia, donde las esposas/os de electos locales y altos cargos sí deben hacerlo. 
- Y en Hungría, donde esta obligación afecta a los familiares que conviven con altos cargos.

\section{Declaración de regalos}

La declaración se exige a partir de un valor relevante, pues por debajo de ciertas cantidades haría engorroso e inútil el volumen de información existente. En la Unión Europea, para los comisarios se ha establecido en 150 euros la cantidad a partir de la cual hay que declarar el regalo (y entregarlo al patrimonio de las instituciones europeas).

Por países, la situación es la siguiente: enn Letonia la declaración es obligatoria para todos los responsables públicos;

- en Polonia sólo es obligatoria para altos cargos y electos locales;

- en Hungría esta regla sólo obliga a los miembros del Parlamento; en España, Reino Unido y Alemania la norma obliga a altos cargos y miembros del gobierno.

Con respecto a los parlamentarios, esta obligación se requiere siempre en Francia, pero en Alemania sólo afecta a regalos de más de 5.000 euros, y en el Reino Unido cuando el regalo tiene un valor que es superior al 1\% de su salario.

\section{Seguridady control en el acceso a información}

En todos los países los funcionarios deben respetar la obligación de mantener en secreto la información confidencial. En concreto, hay sanciones disciplinarias e incluso penales por incumplimiento de tal deber en Francia, España, Polonia y Hungría.

Los parlamentarios también tienen deber de secreto y confidencialidad en Francia, Reino Unido, Estonia, Polonia, Hungría y España.

En todos los países, estos deberes de confidencialidad y los consiguientes sistemas de control en el acceso a la información son regulados con especial detalle para los miembros de bancos centrales, el Tesoro y las agencias reguladoras, pues en estos casos la filtración o el mal uso de la información pueden permitir enriquecimientos directos o indirectos muy notables. Los miembros de los órganos de dirección y los empleados de los Bancos Centrales deben guardar secreto de cuantas informaciones conocieran por el ejercicio de sus cargos, y esta obligación se extiende a después de cesar del cargo. También los responsables y funcionarios de las agencias reguladoras deben guardar riguroso secreto de las informaciones privilegiadas que tengan por su presencia en deliberaciones colectivas o por el ejercicio de su cargo. En España, para evitar el uso privilegiado de información tanto en la Agencia Nacional del Mercado de Valores como en el Banco Central, se exige a su personal que informe a los órganos superiores de su interés en la compra o venta de acciones de sociedades con carácter previo a la compra o venta, dichas operaciones sólo podrán realizarse bajo autorización expresa y se establece un periodo en el cual los valores adquiridos no podrán ser enajenados, a efectos de evitar actividades especulativas basadas en información privilegiada.

Declaración de intereses privados en gestión de contratos, toma de decisiones, o informes relevantes

Para los altos cargos, en Portugal se requiere una declaración formal que incluya información de los tres años previos al nombramiento, en España la declaración formal se refiere a los dos años previos, además, deben declararse al tomar posesión, y cuando se modifiquen las circunstancias, las actividades que se vengan desarrollando y que sean compatibles. Esa información permite conocer intereses 
relevantes para la gestión de contratos, la toma de decisiones o la emisión de informes relevantes, de forma que se pueda controlar la existencia de conflictos de interés.

Para cargos electos locales es precisa la declaración de intereses en Alemania. Tanto los electos locales como los parlamentarios deben declarar sus intereses en España.

En el Reino Unido esta declaración es precisa siempre para todos los empleos públicos (incluidos los electos locales), además, cada vez que haya un interés que pueda llevar a pensar razonablemente a otras personas en su influencia indebida sobre la decisión, ese interés debe ser declarado. La declaración incluye información sobre intereses familiares y de personas muy cercanas.

Los parlamentarios británicos deben asegurar en toda intervención que no existe conflicto de interés con el tema a debate y deben cumplimentar una declaración formal que incluya diez categorías de intereses registrables, así:

- Consejos de Administración en empresas públicas o privadas por las que reciban remuneración.

- Cualquier empleo, oficio o profesión remunerada.

- Clientes, con exposición de los nombres de sus clientes y la naturaleza de su negocio.

- Donaciones (sponsorships) para campaña o apoyo material de cualquier tipo.

- Regalos que excedan del 1\% de su salario.

- Viajes propios o familiares financiados con fondos ajenos.

- Regalos provenientes de países extranjeros.

- Propiedades inmobiliarias y terrenos.

- Acciones en sociedades.
- Otros intereses misceláneos, aunque no sean pecuniarios.

En general, no hay que olvidar que la regulación en conflictos de interés británica es la más antigua pues data de 1889, y que su enfoque actual se basa en la idea de que evitar los conflictos de interés es un aspecto más de la implantación de los estándares éticos en la vida pública. En términos generales, el principio clave en esta materia es que todo responsable público en Gran Bretaña debe declarar todo interés pecuniario o no pecuniario que pueda ser razonablemente considerado por otras personas como influyente en sus acciones.

En los otros países estudiados no se requiere declaración formal para ningún responsable público, aunque ello no implique que los intereses que puedan afectar al adecuado cumplimiento del cargo no deban ser comunicados.

\section{Información pública de las declaraciones} de intereses, ingresos o patrimonio

La publicidad de las declaraciones no es muy común, sólo en Letonia son públicas todas las declaraciones, incluidas las de los funcionarios. Sin embargo, en Francia y Hungría no son públicas ninguna. Siguiendo la tendencia general de su sistema, en Polonia sí son públicas las declaraciones de electos locales, no las del resto.

En Italia y Alemania sólo son públicas las declaraciones de ingresos relevantes de los parlamentarios. En el Reino Unido, las declaraciones de interés de los parlamentarios sí son públicas, también son públicas las declaraciones de regalos. En España, son públicas las declaraciones de patrimonio de los miembros del Gobierno, pero las declaraciones de los parlamentarios y de los electos locales son sólo públicas a petición de personas que justifiquen su interés. 
En Portugal, son públicas las declaraciones de los electos locales, altos cargos y parlamentarios, ocupando, junto a Letonia, el puesto de país más volcado a la transparencia.

\section{Restricciones en empleo posterior al cese}

En España y Portugal, tras el cese, los altos cargos no pueden aceptar nombramiento en empresas con las que tuvieron relaciones regulatorias, contractuales o directas en el cargo. En España, el periodo de "cuarentena" es de dos años, mientras que en Portugal es de tres años. En concreto, la normativa española establece lo siguiente:

"Durante los dos años siguientes a la fecha de su cese los altos cargos no podrán desempeñar sus servicios en empresas o sociedades privadas relacionadas directamente con las competencias del cargo desempeñado. Se considera que existe relación directa en cualquiera de los siguientes supuestos de hecho:

Que los altos cargos, sus superiores a propuesta de ellos o los titulares de sus órganos dependientes, por delegación o sustitución, hubieran dictado resoluciones en relación con dichas empresas o sociedades.

Que hubieran intervenido en sesiones de órganos colegiados en las que se hubiera adoptado algún acuerdo o resolución en relación con dichas entidades.

No se incurrirá en incompatibilidad cuando se reincorporen a empresas en las que ya desarrollaron su actividad profesional, siempre que la actividad que vayan a desempeñar en la empresa privada lo sea en puestos de trabajo que no estén directamente relacionados con las competencias del cargo público ocupado, ni puedan adoptar decisiones que afecten a éste.

Una vez abandonado el cargo, durante los dos años establecidos en la norma, deberán comunicar a la Oficina de Conflictos de Interés, con carácter previo al inicio, las actividades que pretenden desarrollar. La Oficina se pronunciará en el plazo de un mes sobre la procedencia de tal actividad.

Tampoco podrán, en los dos años posteriores al cese, celebrar por sí mismos o a través de sociedades donde tengan más del 10\% de la acciones, contratos con las Administraciones públicas".

En Hungría, Italia y Alemania no hay esas restricciones para altos cargos con carácter general. En Polonia, antes de cesar como alto cargo hay que pedir autorización para nombramientos externos.

En el Reino Unido (2 años) e Italia (2 años) los funcionarios tienen restricciones y control en el empleo posterior al cese. En el Reino Unido deben informar, además, de las ofertas de empleo que reciban, tanto de empresas como de ONG's. En Polonia tienen restricciones de un año los electos y los funcionarios. Todas estas restricciones se refieren a empresas u organizaciones con las que tuvieron relaciones en el cargo.

En Francia, está muy regulada la "cuarentena" para los funcionarios, existe un periodo de cinco años de restricción y se exige autorización expresa para pasar a un empleo en el sector privado. El control y detección de incompatibilidades y de las violaciones de las cuarentenas se realiza fundamentalmente a través del control jerárquico. Pero existen tres comisiones profesionales de ética (una para el servicio civil central, otra para el servicio civil regional y local, y otra para los servicios 
de salud) que deben ser consultadas antes de abandonar el servicio civil y aceptar una posición en el sector privado. Estas comisiones pueden abrir un procedimiento, con audiencia a las partes afectadas, para acumular todos los datos relevantes y emitir una resolución que dé respuesta a la consulta. La resolución se remite a la autoridad administrativa competente, quien tiene la competencia legal para emitir la decisión final. La decisión puede declarar el puesto a cubrir en el sector privado como compatible, incompatible o compatible bajo ciertas condiciones.

\section{Restricciones y control de regalos}

En todos los países, están prohibidos los regalos que puedan influir en la imparcialidad en la toma de decisiones, dado que serían formas más o menos leves de soborno. En todos los países, los jueces tienen normas muy estrictas contra los regalos.

En el Reino Unido, las normas son muy restrictivas, también, en relación a los regalos recibidos por responsables públicos. Así, los altos cargos no pueden recibir ningún regalo cuyo valor esté por encima de 140 libras. Los funcionarios no pueden recibir regalos, y los parlamentarios sólo aquellos que estén por debajo del 1\% de su salario, declarándolos.

En Alemania, España y Francia, los funcionarios, altos cargos y electos locales no pueden recibir regalos que pudieren condicionar mínimamente su imparcialidad en la toma de decisiones.

Restricciones y control de nombramientos concurrentes fuera del sector público (partidos politicos y ONG's

En todos los países, los jueces no pueden pertenecer a partidos políticos ni
ONG's, dado que dicha pertenencia puede influir en su imparcialidad e independencia.

En Letonia, Polonia, Reino Unido, Francia, Alemania, para los altos cargos, existen restricciones a los nombramientos en ONG's cuando afectan repetidamente a la imparcialidad en la toma de decisiones. Si es puntualmente, se puede resolver por la vía de la abstención. Los altos cargos en España, pueden pertenecer y ocupar cargos en ONG's sin ánimo de lucro, siempre que no perciban remuneración por ello. También pueden pertenecer a órganos de dirección de partidos, siempre que ello no comprometa su imparcialidad en el ejercicio del cargo.

En Polonia, Hungría y Reino Unido los funcionarios de alto nivel no pueden ocupar puestos de dirección en partidos.

\section{Abstención}

Quien actúa en nombre del Estado no puede tomar una decisión o intervenir en ella cuando tiene interés privado directo o indirecto en tal decisión, en tal caso debe: o abstenerse de tomar parte en el proceso, o pedir que la decisión la adopte una tercera parte independiente, $y$, además, pedir no recibir información sobre el tema.

Este deber se exige en todos los países estudiados: especialmente bien regulado está en Alemania, Francia y España. Esta institución está regulada en España en la Ley de Régimen Jurídico de las Administraciones Públicas y del Procedimiento Administrativo Común (LRJPA). En su artículo 28 dicha Ley establece que:

"las autoridades y el personal al servicio de las Administraciones en quienes se den algunas de las circunstancias señaladas en el número siguiente de este artículo se abstendrán de intervenir en el procedimiento y lo 
comunicarán a su superior inmediato, quien resolverá lo procedente"; Y añade a continuación que son motivos de abstención: “a) Tener interés personal en el asunto de que se trate o en otro en cuya resolución pudiera influir la de aquél, ser administrador de sociedad o entidad interesada, o tener cuestión litigiosa pendiente con algún interesado. b) Tener parentesco de consanguineidad dentro del cuarto grado (incluye primos) o de afinidad dentro del segundo (incluye cuñados, por ejemplo) con cualquiera de los interesados, con los administradores de sociedades interesadas o con los asesores del proceso, así como compartir despacho profesional con éstos. c) Tener amistad íntima o enemistad manifiesta con alguna de las personas mencionadas en el apartado anterior. d) Haber intervenido como perito o como testigo en el procedimiento de que se trate. e) Tener relación de servicio con persona natural o jurídica interesada en el asunto, o haberle prestado servicios profesionales en los dos últimos años".

En Polonia, el sistema de abstención se regula en el Código de Procedimiento Administrativo, donde se establece la obligación de suspender la participación en un asunto a cualquier responsable público cuya imparcialidad sea cuestionable. Quizás la lista de supuestos que autorizan a tal suspensión es mejorable y la ley es de uso limitado, pero es un interesante modelo.

En Italia, la regulación para los funcionarios - en su mayor parte laboralizados - viene definida en el Código de Conducta, aprobado por Decreto del Ministerio de Administración Pública del 28 de noviembre de 2000. En dicho
Código se establece que "el empleado debe mantener una posición de independencia de cara a evitar la toma de decisiones o la detentación del cargo en situación de real o aparente conflicto de interés". En concreto, no puede desarrollar ninguna actividad que esté en conflicto con el desempeño correcto de sus tareas, $y$ "debe emprender acciones para evitar situaciones y conductas que puedan dañar los intereses o imagen de la Administración" (art. 2.3). De ahí que "deba abstenerse de participar en decisiones o actividades en las que estén implicados sus intereses o los de sus familiares o personas con quienes cohabite" (art. 6.1). Más aún, se debe abstener incluso si no existe conflicto de interés real, "pero su actuación en el asunto puede generar una ausencia de fe en la independencia o imparcialidad de la Administración" (art. 6.3). El problema es que la determinación de las sanciones y faltas queda a lo que se disponga en los convenios colectivos laborales, donde en la práctica no se prevén sanciones ante el incumplimiento de estas normas.

En cuanto a los miembros del Gobierno y altos cargos, existe la Ley $\mathrm{n}^{\circ} 215$ de julio 20, 2004, que entró en vigor en septiembre de 2004. En ella se establece que los políticos, al actuar en cumplimiento de sus obligaciones, deben tener en consideración exclusivamente los intereses públicos y, en caso de conflicto de interés deben abstenerse. También considera que existe incumplimiento de obligaciones cuando debiéndose actuar no se ha actuado. No obstante, la sanción debe producirse no sólo cuando se incumple la norma, sino cuando, además, se ha realizado en "detrimento del interés público", lo cual es una forma de politizar la investigación sobre los incumplimientos y dificultar la real aplicación de la ley. De 
acuerdo a fuentes del actual gobierno, una nueva legislación será elaborada de inmediato.

\section{Restricciones en la propiedad personal o familiar de empresas o acciones de compañias}

En Letonia, Reino Unido, Francia, España y Portugal, todos los responsables públicos tienen restricciones cuando las empresas contratan con el sector público o son reguladas o controladas por el responsable público.

En España los altos cargos tienen una prohibición de tener directa o indirectamente (a través de familiares) participaciones superiores al $10 \%$ en empresas que contraten con la Administración o reciban subvenciones de ellas. Si tuvieren esa participación y son nombrados para el cargo deben desprenderse de las acciones inmediatamente. Para los parlamentarios existen unas incompatibilidades específicas y muy detalladas en el artículo 159 de la Ley de Régimen Electoral, como las actividades de contratista con el sector público o el desempeño de puestos de dirección en cualquier empresa que contrate con la Administración. Tampoco podrán adquirir participaciones superiores al 10\% en ese tipo de empresas con posterioridad a su mandato. En Portugal, cuando un responsable público tenga más del $10 \%$ de las acciones de una empresa, esa empresa no podrá contratar con el sector público.

En Italia sólo los electos locales y parlamentarios tienen estas restricciones. La razón de que no se incluya a miembros del Gobierno y altos cargos, hasta hace poco, era la peculiar situación del Presidente del Consejo de Ministros, en quien recaía la condición de empresario con intereses en muy diversos campos, pero especialmente en el sector audiovisual. Por ello, la Ley $\mathrm{n}^{\circ}$ 215 de 2004, a la que nos referimos antes, no incluye como incompatible con el desempeño de un alto cargo la "propiedad" de empresas.

En Polonia sólo los electos locales tienen explícitamente prohibida la propiedad de empresas.

En Alemania y Hungría no hay restricciones específicas, aunque no hay que olvidar que la obligación de abstención en Alemania es muy exigente y que implica no sólo evitar el conflicto, sino evitar que otros ciudadanos piensen razonablemente que puede haber conflicto de intereses. $\mathrm{Y}$ en Hungría existe una incompatibilidad para cualquier funcionario de ocupar un puesto de trabajo en un área donde existan intereses personales o familiares implicados.

\section{Desinversión}

Cuando alguien se incorpora al sector público y es propietario de empresas o acciones que pueden comprometer su imparcialidad, es necesario proceder a la desinversión.

La desinversión puede realizarse por venta de acciones o de la totalidad de la empresa o puede ser mediante un blind management agreement, que consiste en un contrato con empresa gestora de valores en la que los bienes de los responsables públicos se administran en un fondo "ciego", sin conocimiento de los interesados ni capacidad de dar instruciones. La venta de acciones o de empresa es obligatoria cuando la propiedad de empresa es incompatible con el cargo público. El blind management es recomendable para la gestión de valores que puedan comprometer la independencia, aun cuando sea compatible su propiedad.

Los altos cargos deben desinvertir o contratar un blind management en el Reino Unido, siempre que exista o pueda existir conflicto de intereses. 
En España, el blind management también se requiere para ciertos altos cargos cuando las acciones tengan un valor superior a los 100.000 euros.

\section{Enfoques de detección, investi-} gación, persecución y sanción de los incumplimientos a la normativa vigente en cada Estado

Detección de casos:

Sistemas de denuncia y protección al denunciante

En la detección de casos de incumplimiento de las normas sobre conflicto de interés, es muy importante el instrumento de la denuncia interna o externa a la propia organización donde se desarrolla el caso. Se ha comprobado que, aunque la mayoría de los países promocionan e, incluso, obligan a denunciar los incumplimientos que se conozcan, estas denuncias no se producen salvo cuando hay protección al denunciante, es decir, se protege al denunciante que actuó sensata y honestamente de posibles represalias posteriores.

Sólo Hungría, Reino Unido y Alemania tienen sistema de protección al denunciante. Los otros países aunque promueven la denuncia no tienen sistema de protección, de ahí que las denuncias internas sean casi inexistentes. La protección puede consistir en mantener la anonimidad, en dar garantías de testigo protegido o en asegurar a través de procedimientos y órganos especiales la posibilidad de demandar auxilio a lo largo de toda su vida profesional a quien habiendo denunciado sufra represalias.

\section{Órgano independiente}

Es muy importante, para la detección y posterior denuncia, que el órgano encargado de esa actividad tenga independencia con respecto al Gobierno existente. De lo contrario, existe la posibilidad de manipulación partidista en la aplicación de las normas y presión exitosa a favor de la protección de incumplidores políticamente poderosos.

En esta materia hay muchas diferencias entre países, así:

- Letonia tiene la Oficina para el Combate y la Protección contra la Corrupción. Con cierta independencia, tiene amplios poderes de investigación y persecución, aunque no tiene personal suficiente para desarrollar con eficacia sus tareas. El director de la Oficina es nombrado por cinco años, pero puede ser cesado por el Parlamento (Saeima), en base a una recomendación del Consejo de Ministros. Este Director es el responsable del nombramiento de los jefes de delegación regional y de los funcionarios de la institución. Los poderes de la Oficina son, entre otros: a) Diseñar la estrategia nacional anticorrupción. b) Coordinar la actuación de las instituciones implicadas en la estrategia. c) Monitorear el cumplimiento de la ley sobre conflictos de interés, revisar las quejas, compilar y analizar resultados de su monitoreo. d) Examinar las declaraciones de los responsables públicos. e) Acusar a los incumplidores e imponer sanciones. f) Llevar adelante procesos de investigación y acciones operativas para descubrir incumplimientos. g) Monitorear el cumplimiento de las normas sobre financiación de partidos políticos.

- En Portugal es el Tribunal Constitucional quien detecta e investiga. Su labor se realiza mediante la revisión y examen de las declaraciones de actividades que todo responsable público obligado a ello debe realizar en un plazo de 60 días ante dicho Tribunal, en dichas declaraciones se debe declarar la inexistencia de incompatibilidades o impedimentos para ejercer el cargo. Si no se remiten en el plazo establecido, el Tribunal da otros 30 días de 
plazo, transcurridos los cuales el responsable público pierde su cargo. También están obligados los Secretarios de los ministerios y entes locales a remitir al Tribunal los nombres de todas las personas que ocupan cargos relevantes en sus organizaciones y la fecha en que tomaron posesión. La independencia del Tribunal está fuera de duda.

- En Hungría y Alemania, sin embargo, no hay órgano específicamente encargado, sino que corresponde al superior jerárquico esa labor de detección y control.

- En Polonia se usa para la detección e investigación la jerarquía, la Oficina de Apelaciones para el Autogobierno y la Oficina del Tesoro (para el control en el nivel local-prefecturas), la Cámara de Control y el Ombudsman.

- En Reino Unido no hay un órgano especializado, pero en el nivel central de gobierno le corresponden a la Oficina Nacional de Auditoría los controles de eficacia y eficiencia. Y en el nivel local es la Comisión de Auditoría quien realiza controles de eficacia y eficiencia. También en el nivel local la conducta de los "prefectos" o alcaldes es controlada por los Standards Boards for England, Scotland and Wales que comenzaron a recibir denuncias en 2002. Y la revisión del sistema en su conjunto corresponde al Committee on Standards in Public Life. Este Comité tiene una independencia con respecto al Gobierno, pues sus miembros son elegidos por su prestigio moral y depende del Parlamento, donde es comité permanente. El Comité no impone sanciones, pero hace investigaciones y propone recomendaciones muy detalladas y de gran impacto. Recientemente, ha realizado su $10^{\circ}$ Informe sobre el cumplimiento de los "Siete Principios Éticos" en la vida pública, que se ha publicado en 2005.
- En Francia no hay un órgano independiente. Actúan en la detección y análisis la Comisión por la Transparencia en las Finanzas Públicas que analiza las declaraciones de patrimonio, y tres Comisiones Profesionales de Ética (para autorizar el empleo en el sector privado a los funcionarios).

- En Italia, para los miembros del gobierno y altos cargos detecta e investiga los conflictos de interés en el sector de las telecomunicaciones la Autoridad de la Comunicación, mientras que en el resto es la Autoridad Reguladora de la Competencia. También hay un Alto Comisionado para la prevención y combate de la Corrupción.

- En España hay un Oficina de conflictos de interés para los altos cargos y miembros del gobierno sin independencia, dado que depende del Ministerio de Administraciones Públicas. El resto, se detecta a través de la jerarquía.

- Finalmente, para los parlamentarios, en todos los países, el control se realiza en el interior de las Cámaras.

\section{Investigación}

La investigación criminal es realizada por el Ministerio Público en todos los países. En Portugal, hay un Directorio Central para la Investigación del Crimen Económico y Financiero y la Corrupción, que es parte del Poder Judicial. En Francia, además de la Fiscalía, es importante el papel de la "Comisión contra el Lavado de Dinero" quien ayuda en las investigaciones. En Polonia, es la Agencia de Seguridad Interna quien ayuda si hay delito.

En España existe una Fiscalía especial anticorrupción. Dicha Fiscalía fue creada de forma consensuada entre gobierno y oposición en 1995 como consecuencia de los escándalos de corrupción de la primera 
mitad de los 1990 y la creciente preocupación de la ciudadanía ante tales excesos. Forma parte del Ministerio Público español, con el que comparte las normas de funcionamiento de las Fiscalías. Esta Fiscalía está apoyada por varias unidades especializadas, una dependiente del Ministerio de Hacienda (con cuatro inspectores de Hacienda y seis inspectores adjuntos), otra dependiente de la intervención del Estado (con dos inspectores y tres administrativos) y otras dos policiales, una dependiente de la Guardia Civil y otra de la policía judicial (con 25 miembros en total). También forman parte de la Fiscalía 11 fiscales especializados en criminalidad económica y fraude fiscal y 21 empleados de colaboración. Todas las unidades y los fiscales dependen del Fiscal Jefe.

El Fiscal Jefe anticorrupción es nombrado por el Gobierno, a propuesta del Fiscal General del Estado, el cual, a su vez, es nombrado a propuesta del gobierno. El Fiscal General del Estado trabaja bajo las órdenes del gobierno, aunque posee teóricamente un cierto nivel de independencia en su trabajo. No obstante, puede dar instrucciones al fiscal anticorrupción y, en caso de discrepancia, tras someterlo a los criterios de órganos de la fiscalía, prevalece su opción sobre la del fiscal anticorrupción. El Ministerio Público, en consecuencia, no tiene la independencia que sí tiene el poder judicial en España. No obstante, no es fácil para un fiscal archivar un caso arbitrariamente, pues el Juez de Instrucción tiene la decisión final sobre la materia. Hasta el momento, la presión de los gobiernos sobre los fiscales generales ha sido siempre intensa, y normalmente éstos han favorecido al gobierno que los nombró. Sin embargo, el hasta hace poco fiscal jefe anticorrupción - Carlos Jiménez Villarejo - demostró una alta integridad e independencia, lo que le costó, finalmente, el puesto. Su sucesor ha optado por un perfil menos relevante y combativo, aun cuando la institución mantiene su eficacia.

La Fiscalía Anti-Corrupción es competente sobre dos grandes categorías de infracciones: las infracciones económicas y las infracciones cometidas por agentes públicos en el ejercicio de sus cargos. Ello incluye un enorme conjunto de delitos y posibles actuaciones, por lo que, en la práctica, de acuerdo con instrucciones internas de la Fiscalía General, se reserva su actuación para supuestos de importancia peculiar, por ejemplo, cuando está involucrado un alto cargo nacional o local, o cuando la importancia económica del delito o la inquietud social requieren su intervención. En el resto de situaciones son los fiscales ordinarios los que actúan. Por su parte, también es importante, como órgano auxiliar, la Comisión para la Prevención del Blanqueo de Capitales y las Infracciones Financieras, con su servicio ejecutivo, la cual trabaja bajo dependencia del Secretario de Estado de Economía, que la preside.

En relación a las investigaciones de naturaleza administrativa, no las criminales, el órgano encargado suele ser el mismo que está encargado de la detección, cuando existe tal órgano.

- En Letonia es la Oficina para el Combate y la Protección contra la Corrupción, que puede investigar cuentas bancarias y transacciones financieras y tiene acceso a las bases de datos de Hacienda.

- En Hungría es la Oficina de Registro y Control de las Declaraciones Patrimoniales, quien investiga. Puede investigar cuentas bancarias y transacciones financieras y tiene acceso a las bases de datos de Hacienda. 
- En Polonia, la Agencia del Tesoro investiga las declaraciones de los prefectos o alcaldes y de los concejales (veedores).

- En Alemania son los inspectores de Hacienda si hay fraude fiscal, quienes tienen acceso a cuentas bancarias si lo precisan.

- En Italia son la Autoridad de la Comunicación, y la Autoridad Reguladora de la Competencia quienes investigan a los altos cargos y miembros del gobierno.

- En España corresponde a la Oficina de Conflictos de Interés la investigación en relación a los altos cargos.

\section{Imputación y sanción penal}

Corresponde siempre a jueces la imputación y la sanción penal. Veamos ahora los tipos penales existentes.

\section{Delitos y Penas:}

- En Letonia, hay un delito por violar las normas de conflicto de interés y se castiga con penas de hasta cinco años de cárcel si hay daño al interés público.

- En Polonia, se castiga con hasta tres años la falsa declaración de intereses.

- En Reino Unido, hay sanciones penales para los parlamentarios de Escocia, Gales e Irlanda del Norte, por no declarar intereses. Y se puede aplicar aún a alcaldes o prefectos y a concejales (veedores) una sanción penal por no declarar intereses económicos y no abstenerse cuando corresponde.

- En Italia, los miembros del Gobierno pueden ser acusados penalmente por no declarar o declarar falsamente intereses tras ser requeridos a ello por las Autoridades reguladoras.

- En Francia, hay un delito especial: "Búsqueda ilícita de interés". La sanción es de hasta cinco años en prisión y 75.000 euros de multa. También es delito quebrar la cuarentena post-empleo sancionada con hasta dos años de prisión y 30.000 euros de multa.
- En Alemania hay un delito llamado "Aceptación de ventaja" que cubre todo tipo de ventajas, como reducción de precios, recepción privilegiada de préstamos, cenas caras, honorarios especiales por conferencias, favores sexuales, etc.

Sanciones disciplinarias:

En cualquier caso, además de las sanciones penales, existen también sanciones de naturaleza administrativa. La situación es la siguiente:

- Suspensión de salario.

- Es la sanción administrativa normal para funcionarios en todos los países cuando incumplen las normas administrativas sobre conflicto de intereses.

- Dicha sanción también se establece para jueces en España, Francia, Alemania, Italia o Letonia.

- En Polonia, los alcaldes o prefectos y los electos locales pueden ser sancionados con suspensión de salario por incumplimientos de estas normas.

- En el Reino Unido, los parlamentarios que incumplen el Código de Conducta pueden tener esta sanción de suspensión de salario.

\section{- Cese o despido}

- Es la sanción más dura de las administrativas. En todos los países se recoge para sancionar a funcionarios y jueces.

- Los miembros del gobierno y los altos cargos también pueden ser sancionados con despido en Letonia, Polonia, Hungría, Francia, Portugal y España.

- Otras sanciones administrativas existentes:

- Multas.

- Sanciones morales (como la publicación en el Diario Oficial o en el Diario Parlamentario de las violaciones a la norma y los nombres de los autores). 
- Informes al Parlamento de violaciones a las normas.

- Prohibición de volver a asumir un cargo público por hasta diez años.

- Devolución de cantidades indebidamente percibidas.

- Prohibición a las empresas infractoras (por ejemplo, si contratan a funcionarios o altos cargos indebidamente durante el periodo de cuarentena) de contratar con las Administraciones Públicas durante dicho periodo.

\section{Conclusiones y recomendaciones}

La formulación e implementación de una política eficaz de gestión de los conflictos de interés es un reto difícil de alcanzar, no obstante, todo Gobierno que quiera mejorar la legitimidad de los actores políticos, reforzar la confianza en las instituciones democráticas y construir una democracia de mayor calidad, necesita generar y ejecutar tal política. Tras analizar las experiencias europeas, y de cara a la actualización de la política brasileña sobre conflictos de interés en el sector público, se formulan las siguientes conclusiones, a las que se añadirán unas recomendaciones metodológicas:

1) Conviene incluir las políticas sobre conflictos de interés en una estrategia general sobre prevención y combate a la corrupción. Aunque esta opción no se da prácticamente en los países antiguos miembros de la Unión Europea, la experiencia de los nuevos miembros sí nos lleva a recomendar, por coherencia y por la posibilidad de alcanzar sinergias, la articulación de estas políticas en el marco de una estrategia general de prevención y combate a la corrupción. La clave es que esta estrategia sea fruto del mayor consenso político y social posible y que considere todos los aspectos relevantes de una estrategia eficaz: marco estructural, medidas de prevención, instrumentos eficaces de detección e investigación, y sistema congruente de sanciones.

2) La opción por incluir esta política en una estrategia de lucha contra la corrupción, no impide que se acompañe la misma de una opción positiva y proactiva, definiendo y consensuando los valores y principios del servicio público. Más bien al contrario, es conveniente acompañar la estrategia represiva de una estrategia integradora, de ahí que sea conveniente establecer estándares éticos generales y claros sobre la conducta en la vida pública. El modelo británico puede ser de gran ayuda en este proceso.

3) Una política eficaz exige la aprobación de marcos legales (administrativos y penales) que, tras someterse a rigurosas técnicas de elaboración normativa y a estudios de impacto, permitan una implantación efectiva de las políticas de conflicto de interés. El marco legal no deja de ser una consagración formal de acuerdos políticos y sociales sobre las reglas de moralidad a exigir al sector público, por ello, requiere, además, para su plena implantación una consagración operativa a través de instituciones y mecanismos adecuados. La consagración operativa exige, para empezar, un servicio civil de carrera que sirve objetivamente el interés general y un poder judicial independiente e imparcial. El modelo alemán de derecho penal y administrativo es un buen ejemplo a analizar sobre calidad normativa y sistema judicial. El modelo francés es un buen caso de estudio sobre organización y "ethos" del servicio civil. El modelo británico también merece ser estudiado, especialmente el modelo judicial y de servicio civil. 
4) Una conclusión, tras los análisis de los instrumentos y medidas utilizados en los países estudiados, es que hay que regular cuidadosamente la recusación y la abstención en la toma de decisiones. Si este instrumento funcionara adecuadamente, los demás probablemente serían meros complementos. Ciertamente, es un instrumento que exige un desarrollo moral por parte de los actores públicos muy elevado, de ahí que por sí mismo no baste, no obstante, la regulación y articulación del mismo en Alemania merece ser estudiado.

5) Conviene regular y gestionar adecuadamente las declaraciones obligatorias. De ellas, las declaraciones de ingresos no parecen absolutamente necesarias si hay declaración de intereses y patrimonio. Pueden ser convenientes para cargos políticos y electos locales, no parece que sea necesario obligar a todos los funcionarios a cumplimentar tal declaración. España y Portugal tienen modelos interesantes en esta materia. Sin embargo, las declaraciones de patrimonio son muy útiles para detectar enriquecimientos incomprensibles, especialmente de los altos cargos y electos locales. También permiten detectar posibles conflictos de interés entre los parlamentarios. En esta materia, se puede optar por señalar categorías de funcionarios en riesgo y obligar sólo a ellos a rellenar esta declaración. El modelo húngaro es interesante en esta materia. Finalmente, en relación a las declaraciones de los miembros de la familia, puede ser útil, pero si se convierte en obligatoria tal vez choque con principios constitucionales de privacidad, de ahí que pueda ser regulada como voluntaria, sobre todo para los altos cargos del ejecutivo y los electos locales.

6) En teoría, es conveniente prohibir o, al menos, limitar para todos los servidores públicos la tenencia de empleos fuera de la Administración. No obstante, ello requiere unos salarios dignos y suficientes, de ahí que lo mejor sea establecer la incompatibilidad entre empleos públicos pero ser flexible con empleo en el sector privado que no comprometa la imparcialidad, con la excepción de jueces, altos cargos y miembros del gobierno, quienes deben tener incompatibilidad absoluta. El modelo español es interesante para altos cargos, el modelo francés lo es para funcionarios, el modelo alemán para jueces y el británico para electos locales.

7) Es más conveniente prohibir la aceptación de regalos a partir de un valor superior a, por ejemplo, diez euros, que establecer reglas complejas sobre cuándo aceptarlos, cuándo declararlos, o cuándo incorporarlos al patrimonio del Estado. La única excepción serían los regalos oficiales, que deberían inmediatamente incorporarse al patrimonio estatal.

8) La declaración formal de intereses y actividades propios y familiares es otro de los fundamentos del sistema. Establecer un modelo único y controlar su cumplimentación y actualización es fundamental para un buen sistema de prevención de conflictos de interés. Esta declaración debería ser cumplimentada por todos los responsables públicos, con la excepción, tal vez, de los funcionarios de nivel medio e inferior que no desarrollen actividades reguladoras o inspectoras. El modelo británico es un buen ejemplo del que aprender.

9) La publicidad de las declaraciones es conveniente para loa cargos electos y altos cargos del ejecutivo, pero debe asegurarse el respeto a la protección de datos personales. Para los funcionarios, no parece que sea precisa la publicidad generalizada, bastaría con que fuera disponible para los responsables de su control. El 
modelo portugués y el de Letonia es interesante en este aspecto.

10) Es necesario limitar las posibilidades de empleo tras dejar el cargo público, pues con ello se evitan sobornos diferidos. El modelo francés es muy interesante para los funcionarios. El modelo español y portugués es interesante para los altos cargos o cargos de nombramiento político. El modelo francés convendría aplicarlo a jueces con adaptaciones. El modelo español convendría adaptarlo para ciertos electos locales en grandes ciudades.

11) También es conveniente limitar las actividades externas al servicio público no remuneradas - mientras se detenta un cargo público de alto nivel o con capacidades de decisión o regulación elevadas. Ello implica establecer límites para la detentación o ejercicio de puestos en ONG's, partidos políticos o asociaciones que puedan afectar a la imparcialidad del responsable público correspondiente. El modelo británico es interesante al respecto.

12) Es preciso prohibir y, en su caso, sancionar el uso de información reservada para fines privados. Para ello, conviene establecer un mapa de riesgos de filtración de información y, para todos los órganos y servicios afectados establecer prohibiciones específicas y controles detallados. Así como establecer un tipo penal relativo al uso de información privilegiada. El control de la compra y venta de acciones o títulos del Tesoro debe estar incluido.

13) La experiencia del caso italiano y los datos generales demuestran que es necesario restringir los derechos de propiedad en compañías privadas mientras se ostenta cargo público. Especialmente, se ha de prohibir la propiedad directa o indirecta de empresas que estén bajo el control o regulación del responsable público, así como la propiedad o la tenencia de acciones de empresas que contraten con el sector público. Estas prohibiciones afectan sobre todo a altos cargos, electos locales y parlamentarios, pero también deben regularse para funcionarios. El modelo español es interesante en este aspecto.

14) Nada de lo anterior es suficientemente eficaz si no se establecer un sistema de detección e investigación que funcione, incluyendo un órgano independiente de detección e investigación. Proteger suficientemente a los denunciantes internos es, también, uno de los instrumentos del sistema. En protección del denunciante, los modelos británico y alemán son útiles. En cuanto a órgano independiente, el modelo de Letonia puede ser también digno de análisis. Como órgano de investigación penal, la Fiscalía especial anticorrupción, de España, es un modelo con ventajas indudables.

15) Las sanciones penales y administrativas deben ser compatibles y complementarias. El modelo francés es muy interesante, aunque también el modelo alemán y polaco pueden ser útiles.

16) En todo caso, la formulación e implantación debe considerar las peculiaridades de estas políticas: salvo en casos de escándalo evidente producen grandes costes políticos y beneficios difusos y a largo plazo. Por ello, son difíciles de llevar a la agenda gubernamental, salvo si hay grave escándalo. Pero, sobre todo, son muy difíciles de implantar. Cuanta más corrupción más difíciles de implantar. De ahí que no se pueda dilatar el proceso, pues la corrupción sin prevención y represión siempre avanza, nunca retrocede por sí misma.

\section{Propuestas metodológicas}

- Hay que tener clara la lección a aprender en cada caso. 
- Es preciso saber captar la atención de los hacedores de políticas - policymakers para tener apoyo en la generación de valor.

- No se pueden aprender lecciones sin saber bien dónde se encuentran las lecciones.

- Pero las lecciones requieren saber construir relaciones de causa-efecto que expliquen el por qué de los éxitos y fracasos y los beneficios para el programa, ello demanda, a su vez, superar las anécdotas nacionales.

- Enseñar lecciones implica construir un programa que conecte con las necesidades y el entorno al que se dirige, por ello cada programa debe adaptarse a las necesidades nacionales.

- Al final hay que conseguir que a la pregunta “¿debemos adoptarlo?” los decisores nacionales respondan "sí" porque entienden los intereses de fondo que están en juego, porque asumen una visión política de largo alcance.

- También hay que ser capaces de ayudar a que la pregunta "¿podemos adoptarlo?" sea respondida de forma positiva, porque se garantizan fondos económicos y capacitación en competencias requeridas para la implantación del programa.

- Cada proyecto debe tener un único objetivo, una meta claramente definida y un diseño sencillo para reducir puntos de veto.

- Una vez en marcha, el aprendizaje es un proceso continuo, en el que se aprende de lo que se hace dentro y, nuevamente, de lo que funciona fuera. La transferencia de conocimientos es parte inseparable de la forma de hacer políticas en el siglo XXI.

(Artigo recebido em setembro de 2006. Versão final em outubro de 2006)

\section{Notas}

${ }^{1}$ Responsable público se refiere a todo tipo de cargo público, sea electo o de nombramiento, sea en el gobierno central o en gobiernos sub-nacionales.

${ }^{2}$ No obstante, en algunos países se puede compatibilizar el alto cargo con la presencia en representación del Estado como consejero de empresas públicas o con participación pública. Esta actividad extra no suele ser remunerada, pero en general falta una regulación específica de los conflictos de interés a que pueda dar lugar en los casos en los que la empresa es mixta.

\section{Referencias bibliográficas}

BeEtham, David. Defining and measuring democracy. London: SAGE, 1994.

Dalton, Russel. Political support in advanced industrial countries. Critical citizens: Global support for democratic government. Pipa Norris (ed.), Oxford: Oxford University Press. 
Della Porta, Donatella. Social capital, beliefs in government, and political corruption. Disaffected democracies, Susan J. Pharr; Robert D. Putnam (eds.), Princeton: Princeton University Press. Della Porta, Donatella.; VAnucci, Alberto. "The perverse effects" of political corruption. Political corruption, Paul Heywood (ed.), Oxford: Blackwell Publishers, 1997.

Dimaggio, Paul; PoxELL, Walter. The iron cage revisited: institutional isomorphism and collective rationality in organizational fields. American Sociological Review, no 48, pp. 149-160, Abr. 1983.

Gomá, Ricard; Subirats, Joan. Políticas públicas en España. Barcelona: Ariel, 1987.

INGLEHART, Ronald. Modernización y postmodernización. Madrid: Centro de Inverstigaciones Sociológicas, 1998.

Inglehart, Ronald, ... [et al]. Human beliefs and values. México: Siglo XXI Editors, 2004.

Kauffman, Daniel; Kraay, Aart; Zoido-lobatón, Pablo. Governance matters: from measurement to action. Finance and Development. Fondo Monetario Internacional. Washington, DC: 2000.

KIngDom, John. Agendas, alternatives and public policies. Nueva York: Harper Collins, 1995.

Kjellberg, Francesco. Corruption as an analytical problem: some notes on research in public corruption. In: International Political Science Association, XVIII World Congress - 2000, Quebec. Memorial Articles.

Kilksdberg, Bernardo. Hacia un Nuevo perfil del Estado en América Latina: los cambios en las percepciones y las demandas de la ciudadanía. Revista del CL AD Reforma y Democracia. Caracas: $\mathrm{n}^{\circ}$ 32, junio, pp. 51-88, 2005.

Levi, Margaret. Social and unsocial capital. Politics and Society. Thousand Oaks: $\mathrm{n}^{\circ} 24$, pp.45-55.

LowI, Theodore J. Four systems of policy, politics and choice. Public Administration Review. Vol. 32, no 4, pp. 298-310, 1972.

March, James; Olsen, Johan. Rediscovering institutions. New York: The Free Press, 1989.

OCDE. Managing conflicts of interest in the public service. Paris: OCDE, 2004.

Pfeffer, Jeffrey. Managing with power. Boston, MA: Harvard Business School Press, 1992.

Pharr, Susan J. Officials misconduct and public distrust: Japan and the Trilateral Democracies. Disaffected Democracies, Susan J. Pharr; Robert D. Putnam (eds.), Princeton: Princeton University Press, 2000.

Pharr, Susan J.; Putnam, Robert D. (eds.) Disaffected Democracies. Princeton: Princeton University Press, 2000.

RaILE, Eric. Managing conflicts of interest in the Americas: a comparative review. Washington, DC: U.S. Office of Government Ethics, 2004.

Rothstein, BO.; Uslaner, Eric M. All for all: equality and social trust. LSE Health and Social Care Discussion Paper. The London School of Economics and Political Science. London: $\mathrm{n}^{\circ}$ 15, 2005.

Sabatier, Paul A. The need for better theories. Theories of the public policy process, Paul Sabatier. Boulder, Colorado: Westview Press, 1999.

Schelding, Thomas. Choice and consequence: perspectives of an errant economist. Cambridge: Harvard University Press, 1984. 
Sustein, Cass; Thaler, Richard. Libertarian Paternalism is not an oxymoron. The University of Chicago Law Review. no 4, pp. 73-82, 2003.

Tanzi, Vito; Davoodi, Hamid. Corrupción, inversión pública y crecimiento. Gestión y Análisis de Política Pública. Madrid: $\mathrm{n}^{\circ}$ 21, pp. 73-82, mayo-agosto, 2001.

VILLORIA, Manuel. La corrupción politica. Madrid: Síntesis, 2006. 


\section{Resumo - Resumen - Abstract}

\section{Políticas e práticas para gerir conflitos de interesse na Europa: uma visão comparada} Manuel Villoria

Este artigo expõe, de forma sumária, os diversos enfoques que nove países europeus - seis antigos membros da União Européia (França, Alemanha, Itália, Espanha e Reino Unido) e três novos (Hungria, Letônia e Polônia) - estão usando para gerenciar os conflitos de interesses no setor público. A primeira parte apresenta o marco conceitual e as definições de corrupção e conflitos de interesse no setor público. Em seguida, trata das razões existentes por trás das políticas de regulação e tratamento dos conflitos de interesse, ressaltando a importância dessas políticas para o funcionamento adequado da democracia. Explica as características, peculiaridades e dilemas da política pública de regulação no contexto das teorias e enfoques sobre políticas públicas. O artigo também examina os pontos comuns nas estruturas, métodos e processos utilizados para gerenciar os conflitos de interesse nos países estudados, além de esclarecer as principais diferenças nos marcos legais, meios de implementação, mecanismos de avaliação e meios de execução. Inclui uma visão crítica das vantagens e desvantagens relacionadas à utilidade dos instrumentos empregados e finaliza com recomendações sobre como formular e implementar políticas desse tipo.

Palavras-chave: conflito de interesses, políticas públicas, União Européia

\section{Políticas y prácticas para gestionar los conflictos de interés en Europa: una visión comparada.}

Manuel Villoria

Este informe expone de forma sumaria los diversos enfoques y aproximaciones que nueve países de la Unión Europea - seis antiguos miembros (Reino Unido, Alemania, Francia, Italia, España y Portugal) y tres miembros recientes (Letonia, Polonia y Hungría) - están usando para gestionar los conflictos de interés en el sector público. En la primera parte, se presenta el marco conceptual y las definiciones con las que poder entender de qué hablamos cuando hablamos de corrupción y de conflictos de interés en el sector público. Posteriormente, trata de las razones existentes tras las políticas de regulación y tratamiento de los conflictos de interés y la importancia de ellas para el funcionamiento adecuado de la democracia. A continuación, se explican las características, peculiaridades y dilemas de esta política pública en el contexto de las teorías y enfoques sobre políticas públicas. El informe también examina los puntos comunes en las estructuras, métodos y procesos utilizados para gestionar los conflictos de interés en los países estudiados, además de explicitar las principales diferencias en los marcos legales, medios de implantación, mecanismos de evaluación y medios de ejecución. Por último, incluye una visión crítica de las ventajas y desventajas relacionadas con la utilidad de los instrumentos empleados y finaliza con recomendaciones relativas a cómo formular e implantar políticas de este tipo.

Palabras-clave: Unión Europea, políticas públicas, conflictos de interés. 


\section{Policies and practices for managing conflicts-of-interest in nine EU member states: a comparative review}

Manuel Villoria

This paper provides a brief overview of approaches that nine European countries - six old EU members (France, Germany, Italy, Portugal, Spain and the United Kingdom) and three new EU members (Hungary, Latvia and Poland) - are using to manage conflicts of interest in the public sector. It starts by introducing a conceptual framework and definitions of conflict of interest in the public sector. It then outlines the rationale of the policies on conflicts-of-interest and their importance for the proper functioning of the democracy. From the concept and the theory of public policies, it tries to explain the characteristics, singularities and the dilemmas of these policies. The paper also examines the common grounds in structures, methods and mechanisms used to manage conflict of interests in the nine selected EU member countries, as well as the differences among their legal frameworks, means of implementation, evaluation mechanisms and means of enforcement. Finally, it includes a critical assessment of the advantages and disadvantages of those mechanisms in terms of their adequacy and concludes by drawing some recommendations in formulating and implementing such policies.

Key words: European Union - EU, public policies, conflicts-of-interest.

Manuel Villoria

Director del Departamento de Gobierno, Administración y Políticas Públicas del Instituto Universitario de Investigación José Ortega y Gasset y Catedrático de Ciencia Política y de la Administración de la Universidad Rey Juan Carlos (España). Doctor en Ciencia Política y Sociología por la Universidad Complutense de Madrid. Contato: <manuel.villoria@urjc.es> 